\title{
A Supramolecular Container-Mediated Surface Engineering Approach for Regulating the Biological Targeting Effect of Nanoparticles
}

Meng Zhao,,$_{+,+,}$Zeyu Liang,,$^{\dagger,+,}$ Bo Zhang,,$^{o, \perp}$ Qiyue Wang,,$^{+, \perp}$ Jiyoung Lee,,$^{\dagger}$ Fangyuan Li,,$^{\dagger}$ Qi Wang, ${ }^{\circ}$ Da Ma ${ }^{\perp}$ and Daishun Ling ${ }^{\dagger, t}, \xi, *$

${ }^{\dagger}$ Institute of Pharmaceutics, College of Pharmaceutical Sciences, Zhejiang University, Hangzhou 310058, China

$\$$ Hangzhou Institute of Innovative Medicine, College of Pharmaceutical Sciences, Zhejiang University, Hangzhou 310058, China

$\S$ Key Laboratory of Biomedical Engineering of the Ministry of Education, College of Biomedical Engineering \& Instrument Science, Zhejiang University, Hangzhou 310027, China

${ }^{\circ}$ Department of Chemistry, Zhejiang University, Hangzhou 310027, China

${ }^{\Delta}$ Department of Chemistry, Fudan University, Shanghai 200433, China

${ }^{\perp}$ These authors contributed equally to this work.

*Correspondence should be addressed to: Tel.: +86-571-88208623. E-mail: lingds@zju.edu.cn. 


\section{Experimental section}

Materials: All reagents and solvents were obtained commercially and used without further purification. Ferric trichloride hexahydrate $\left(\mathrm{FeCl}_{3} \cdot 6 \mathrm{H}_{2} \mathrm{O}\right)$, sodium oleate, manganese chloride tetrahydrate $\left(\mathrm{MnCl}_{2} \cdot 4 \mathrm{H}_{2} \mathrm{O}\right)$, 1-hexadecene, gold chloride trihydrate $\left(\mathrm{HAuCl}_{4} \cdot 3 \mathrm{H}_{2} \mathrm{O}\right)$, hexadecyl trimethyl ammonium bromide (CTAB), ascorbic acid, N,N'dicyclohexylcarbodiimide (DCC), N-hydroxysulfosuccinimide sodium salt (NHS), N-(3Dimethylaminopropyl)-N'-ethylcarbodiimide hydrochloride (EDC), dopamine hydrochloride, dimethyl sulfoxide (DMSO), N, N'-dimethylformamide (DMF), spermidine (SP), Arg-GlyAsp (RGD), trifluoroacetate (TFA), rhodamine B isothiocyanate (RITC) were purchased from Aladdin Co. (China). Eicosane, sodium borohydride $\left(\mathrm{NaBH}_{4}\right)$, and oleic acid were purchased from Sigma-Aldrich Co. (USA). Sodium hydroxide $(\mathrm{NaOH})$, silver nitrate $\left(\mathrm{AgNO}_{3}\right)$, ethyl alcohol, acetone, chloroform, hydrochloric acid, nitric acid, n-hexane, anhydrous sodium carbonate $\left(\mathrm{Na}_{2} \mathrm{CO}_{3}\right)$ were purchased from Sinopharm Co. (China). Poly(ethylene glycol) bis carboxy (HOOC-PEG-COOH) and carboxyl poly(ethylene glycol) sulfydryl (HOOC-PEGSH) were purchased from Punsore Biotechnology Co. (China).

Preparation of aCB congener 1: The synthesis of compound $2^{1}$ and compound $3^{2}$ have been reported previously. 2 (40 g, $51 \mathrm{mmol})$ and $\mathbf{3}(81 \mathrm{~g}, 204 \mathrm{mmol})$ were mixed in TFA (370 $\mathrm{mL}$ ) and stirred at $70{ }^{\circ} \mathrm{C}$ for $3 \mathrm{~h}$. The excessive solvent was removed by rotary evaporation and the product was dried. The dried product was washed with water and acetone $(1: 2, \mathrm{v} / \mathrm{v})$ twice and dissolved in water, then the $\mathrm{pH}$ of the solution was adjusted to neutral. The solvent was further removed by rotary evaporation and the product was dried to obtain aCB congener $1 .{ }^{1} \mathrm{H}$ $\operatorname{NMR}\left(500 \mathrm{MHz}, 25^{\circ} \mathrm{C}, \mathrm{D}_{2} \mathrm{O}\right): \delta 6.75(\mathrm{~s}, 4 \mathrm{H}), 5.56(\mathrm{~d}, J=15.4 \mathrm{~Hz}, 2 \mathrm{H}), 5.47(\mathrm{~d}, J=15.7 \mathrm{~Hz}$, 
4H), $5.34(\mathrm{~d}, J=9.0 \mathrm{~Hz}, 2 \mathrm{H}), 5.29(\mathrm{~d}, J=9.0 \mathrm{~Hz}, 2 \mathrm{H}), 5.25(\mathrm{~d}, J=16.3 \mathrm{~Hz}, 4 \mathrm{H}), 4.17(\mathrm{~d}, J=$ $3.8 \mathrm{~Hz}, 1 \mathrm{H}), 4.13(\mathrm{~d}, J=4.3 \mathrm{~Hz}, 1 \mathrm{H}), 4.01(\mathrm{~d}, J=15.4 \mathrm{~Hz}, 2 \mathrm{H}), 3.95(\mathrm{~m}, 4 \mathrm{H}), 3.85(\mathrm{~m}, 4 \mathrm{H})$, $3.04(\mathrm{~m}, 8 \mathrm{H}), 2.03(\mathrm{~m}, 8 \mathrm{H}), 1.70(\mathrm{~m}, 6 \mathrm{H}), 1.66(\mathrm{~s}, 6 \mathrm{H})$.

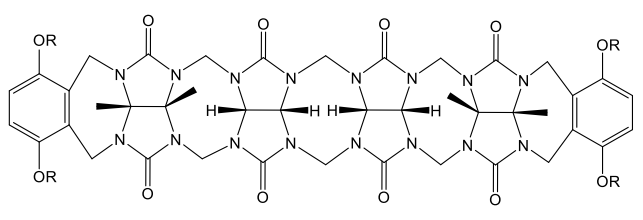

$1 \mathrm{R}=\left(\mathrm{CH}_{2}\right)_{3} \mathrm{SO}_{3} \mathrm{Na}$

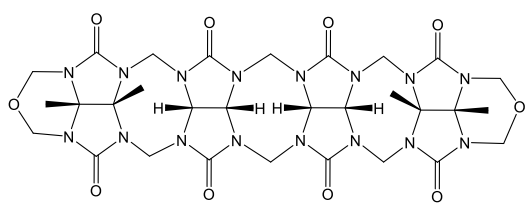

2

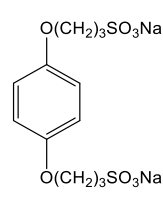

3

Synthesis of iron oxide nanoparticles: $15 \mathrm{~nm}$ iron oxide nanoparticles were synthesized with the method of thermal decomposition. ${ }^{3}$ The iron-oleate complex was first synthesized as the precursor. $5.4 \mathrm{~g}$ of $\mathrm{FeCl}_{3} \cdot 6 \mathrm{H}_{2} \mathrm{O}$ and $18.25 \mathrm{~g}$ of sodium oleate were mixed in a flask with 40 $\mathrm{mL}$ of ethanol, $30 \mathrm{~mL}$ of DI water and $70 \mathrm{~mL}$ of hexane. The mixture was heated to $70{ }^{\circ} \mathrm{C}$ and kept at this temperature for $4 \mathrm{~h}$. Then the organic phase was separated and washed with DI water several times. The excess solvent was removed by rotary evaporation to obtain ironoleate complex. $0.9 \mathrm{~g}$ of iron-oleate complex and $0.14 \mathrm{~g}$ of oleic acid were dissolved in $5 \mathrm{~g}$ of eicosane at room temperature. The reaction mixture was first heated to $80{ }^{\circ} \mathrm{C}$ and kept at that temperature for $2 \mathrm{~h}$. Then, the reaction mixture was heated to $347^{\circ} \mathrm{C}$ with a constant heating rate of $3.3{ }^{\circ} \mathrm{C} / \mathrm{min}$, and kept at that temperature for $30 \mathrm{~min}$ under Ar atmosphere. After the reaction, the mixture containing the nanoparticles was rapidly cooled down to room temperature. Then acetone was added to precipitate the nanoparticles. Finally, the nanoparticles were separated by centrifugation and dispersed in $10 \mathrm{~mL}$ of chloroform.

Synthesis of manganese oxide nanoparticles: $9.5 \mathrm{~nm}$ manganese oxide nanoparticles were also synthesized by thermal decomposition. ${ }^{4} 3.96 \mathrm{~g}$ of manganese chloride tetrahydrate and $12.18 \mathrm{~g}$ of sodium oleate were mixed in a flask with $15 \mathrm{~mL}$ of ethanol, $20 \mathrm{~mL}$ of DI water and 
$35 \mathrm{~mL}$ of hexane. The mixture was heated to $70{ }^{\circ} \mathrm{C}$ and kept at this temperature for $12 \mathrm{~h}$. Then the organic phase was separated and washed with DI water several times. The excessive solvent was removed by rotary evaporation to obtain Mn-oleate complex. $0.62 \mathrm{~g}$ Mn-oleate complex was dissolved in $5 \mathrm{~g}$ of 1-hexadecene at room temperature. The reaction mixture was first heated to $80{ }^{\circ} \mathrm{C}$ and kept at that temperature for $100 \mathrm{~min}$. Then the reaction mixture was heated to $280{ }^{\circ} \mathrm{C}$ with a constant heating rate of $1.9^{\circ} \mathrm{C} / \mathrm{min}$, and kept at that temperature for $5 \mathrm{~min}$ under Ar atmosphere. After the reaction, the mixture containing the nanoparticles was rapidly cooled down to room temperature. Then acetone was added to precipitate the nanoparticles. Finally, the nanoparticles were separated by centrifugation and dispersed in $10 \mathrm{~mL}$ chloroform.

Synthesis of gold nanorods: Gold nanorods were prepared by a seed-mediated method. ${ }^{5}$ First, the seed solution was prepared. $1 \mathrm{~mL}$ of CTAB aqueous solution $(0.2 \mathrm{M})$ and $1 \mathrm{~mL}$ of $\mathrm{HAuCl}_{4}$ aqueous solution $(0.5 \mathrm{mM})$ were mixed and stirred for $2 \mathrm{~min}$, and $50 \mu \mathrm{L}$ of ice-cold $\mathrm{NaBH}_{4}$ aqueous solution $(0.7 \mathrm{mg} / \mathrm{mL})$ was added and stirred rapidly for another $2 \mathrm{~min}$. After stirring, the seed solution was kept for $2 \mathrm{~h}$ at $27^{\circ} \mathrm{C}$. Second, for gold nanorods growth process, $75 \mathrm{~mL}$ of CTAB aqueous solution $(0.2 \mathrm{M}), 67.5 \mathrm{~mL}$ of DI water and $3.75 \mathrm{~mL}$ of $\mathrm{AgNO}_{3}$ solution $(4 \mathrm{mM})$ were mixed and kept at $27{ }^{\circ} \mathrm{C}$ for $15 \mathrm{~min} .7 .5 \mathrm{~mL}$ of $\mathrm{HAuCl}_{4}$ solution (10 $\mathrm{mM}$ ) was added and stirred gently for $15 \mathrm{~min}$. Then $0.1 \mathrm{M}$ ascorbic acid aqueous solution was added to the mixture until the reacted solution turned colorless. Finally, $1.5 \mathrm{~mL}$ of seed solution was added to the above solution and stirred for $2 \mathrm{~min}$ and kept at $27{ }^{\circ} \mathrm{C}$ for $12 \mathrm{~h}$. The reacted solution was centrifuged at $8000 \mathrm{rpm}$ for $15 \mathrm{~min}$ and washed with water twice. Then the gold nanorods were dispersed in $75 \mathrm{~mL}$ of DI water. 
Synthesis of PEG modified nanoparticles: $200 \mathrm{mg}$ of HOOC-PEG-COOH (MW=2000), $30 \mathrm{mg}$ of DCC, $24 \mathrm{mg}$ of NHS, $15 \mathrm{mg}$ of dopamine hydrochloride and $60 \mathrm{mg}$ of anhydrous $\mathrm{Na}_{2} \mathrm{CO}_{3}$ were dissolved in $5 \mathrm{~mL}$ of $\mathrm{DMF}$ and $8.5 \mathrm{~mL}$ of chloroform and then stirred at a temperature of $35{ }^{\circ} \mathrm{C}$. After stirring for $2 \mathrm{~h}$, previously synthesized $1.5 \mathrm{~mL}$ of iron oxide nanoparticles or manganese oxide nanoparticles were added into the mixture solution and continued to stir for $12 \mathrm{~h}$. After the reaction, the product was precipitated with hexane and dissolved in $10 \mathrm{~mL}$ of DI water. The extra reactants were removed by dialysis and ultrafiltration and then IONP-PEG and MONP-PEG were obtained finally.

$15 \mathrm{~mL}$ of gold nanorods and $5 \mathrm{~mL}$ of CTAB solution $(0.2 \mathrm{M})$ were mixed under ultrasound at room temperature. At least $1 \mathrm{~h}$ later, the mixture was stirred for $24 \mathrm{~h}$. After stirring, the solution was centrifuged at $8000 \mathrm{rpm}$ for $7 \mathrm{~min}$ and dispersed in $1 \mathrm{~mL}$ of DI water to get a stock solution. $70 \mathrm{mg}$ of HOOC-PEG-SH (MW=2000) was dissolved in $5 \mathrm{~mL}$ of DI water and the stock solution was added into it. The mixture was stirred at $27^{\circ} \mathrm{C}$ for $24 \mathrm{~h}$. After the reaction, the solution was centrifuged at $8000 \mathrm{rpm}$ for $10 \mathrm{~min}$ and washed with water four times. Finally, GNR-PEG was dispersed in $0.5 \mathrm{~mL}$ of DI water.

Synthesis of spermidine modified nanoparticles: $3 \mathrm{~mL}$ of IONP-PEG, or $6 \mathrm{~mL}$ of MONPPEG, or $0.5 \mathrm{~mL}$ of GNR-PEG ,52 $\mathrm{mg}$ of EDC and $40 \mathrm{mg}$ of NHS were mixed with $3 \mathrm{~mL}$ of MES solution. After shaking for $15 \mathrm{~min}, 8.8 \mathrm{mg}$ of spermidine were added and continually shook for another $3 \mathrm{~h}$.

Synthesis of XNP-CR: $30 \mathrm{mg}$ aCB congener 1 was dissolved in $3 \mathrm{~mL}$ of PBS ( $\mathrm{pH}=7.4)$ and $2 \mathrm{~mL}$ of spermidine modified nanoparticles were added dropwise. The mixture was sonicated in a bath sonicator for $20 \mathrm{~min}$ and then by a tip sonicator at $30 \%$ amplitude for $5 \mathrm{~min}$. 
Finally, after shaking for $12 \mathrm{~h}$, the solution was dialyzed and ultrafiltered with PBS (pH = 7.4) to remove free aCB congener 1 . Then, spermidine modified RGD (SP-RGD) were added dropwise into the above solution. After shaking for $12 \mathrm{~h}$, the product was dialyzed and ultrafiltered with PBS $(\mathrm{pH}=7.4)$ to remove free RGD.

Synthesis of XNP-R: 3.9, 7.8, 15.6, 23.4 and $31.2 \mathrm{mg}$ of RITC labeled RGD (RGD-RITC) and equivalent EDC and NHS were dissolved in $1 \mathrm{~mL}$ of MES solution. After shaking for 15 min, $2 \mathrm{~mL}$ of spermidine modified nanoparticles were added into the solution and continually shook for another $12 \mathrm{~h}$. The product was dialyzed to remove free reactants and catalysts. Meanwhile, XNP-CR were also synthesized with RITC labeled RGD (7.8 mg). The amount of RGD-RITC modified onto XNP-CR and different XNP-R was analyzed by measuring fluorescence intensity of the nanoparticles. The results indicate that the same amount of RGD on the two kinds of nanoparticles will be realized when the reactant ratio of RGD between XNP-R and XNP-CR is 2:1 (Figure S14). Consequently, $15.6 \mathrm{mg}$ of RGD and $2 \mathrm{~mL}$ of spermidine modified nanoparticles were reacted to prepare XNP-R.

Synthesis of RITC labeled nanoparticles: $2 \mathrm{~mL}$ of RITC solution $(1 \mathrm{mg} / \mathrm{mL})$ were added into $5 \mathrm{~mL}$ of XNP-CR or XNP-R solution and stirred for $12 \mathrm{~h}$. After the reaction, the product was dialyzed, ultrafiltered and washed three times to remove free reactants.

Characterization: Transmission electron microscopy (TEM) images were obtained on a transmission electron microscope (Hitachi HT7700, Japan). The hydrodynamic size and zeta potential were measured with a Zetasizer Nano ZS90 (Malvern Instruments, UK) at room temperature. UV-Vis absorption spectra were measured by a UV-Vis-NIR Spectrophotometer UV-3600 (Shimadzu, Japan). ${ }^{1} \mathrm{H}$-nuclear magnetic resonance $\left({ }^{1} \mathrm{H}-\mathrm{NMR}\right)$ spectra were obtained 
by a nuclear magnetic resonance (NMR) spectrometer (Bruker AVIII500M, Switzerland). The concentrations of metal elements in samples were determined by inductively coupled plasma mass spectrometry (ICP-MS, PerkinElmer NexION 300X, USA). All the experiments were performed at $\mathrm{pH}$ of 7.4 .

MR property evaluation: MR properties of IONP-CR, IONP-R, MONP-CR and MONPR were performed on a 9.0 T MR scanner (Time Medical Systems Nova 9T/110, USA). All the nanoparticles were dispersed in distilled water with different Fe or Mn concentrations. The $\mathrm{T} 2$ relaxation times at different $\mathrm{Fe}$ or $\mathrm{Mn}$ concentrations were acquired with the following sequence: $\mathrm{TR}=2000 \mathrm{~ms}, \mathrm{TE}=10,20,30,40,50$ and $60 \mathrm{~ms}$. The T1 relaxation times at different Fe or Mn concentrations were acquired with the following sequence: $\mathrm{TR}=2000 \mathrm{~ms}$, TI $=15$, $60,100,200,400,600,800,1000,1200$ and $1500 \mathrm{~ms}$. Relaxivity value of transverse relaxivity (r2) or longitudinal relaxivity $(\mathrm{r} 1)$ was calculated through the curve fitting of $1 / \mathrm{T} 2\left(\mathrm{~s}^{-1}\right)$ or $1 / \mathrm{T} 1$ $\left(\mathrm{s}^{-1}\right)$ versus Fe or Mn concentration $(\mathrm{mM})$. The T1-weighted MR images were obtained with the following sequence: $\mathrm{TR}=500 \mathrm{~ms}, \mathrm{TE}=7.5 \mathrm{~ms}$ and $\mathrm{FOV}=40 \times 35 \mathrm{~mm}^{2}$. The T2-weighted MR images were obtained with the following sequence: $\mathrm{TR}=2500 \mathrm{~ms}$, $\mathrm{TE}=30 \mathrm{~ms}$ and FOV $=45 \times 45 \mathrm{~mm}^{2}$.

Cell culture: L02 cells, HeLa cells, A549 cells and U-87MG cells were respectively cultured in Dulbecco's Modified Eagle medium (DMEM) and Modified Eagle medium (MEM) supplement with $1 \%$ penicillin/streptomycin and $10 \%$ fetal bovine serum in an atmosphere of $5 \% \mathrm{CO}_{2}$ and $95 \%$ humidified air at a constant temperature of $37{ }^{\circ} \mathrm{C}$.

\section{Cellular uptake:}


(1) confocal laser scanning microscope (CLSM) imaging: U-87MG cells were cultured on confocal dishes $\left(1 \times 10^{5}\right.$ cells/ well) filled with MEM supplement with $10 \%$ fetal bovine serum. The cells were maintained in an atmosphere of $5 \% \mathrm{CO}_{2}$ and $95 \%$ humidified air at a constant temperature of $37^{\circ} \mathrm{C}$. After $24 \mathrm{~h}$ incubation, the medium was replaced with $2 \mathrm{~mL}$ of fresh MEM or DMEM containing RITC-labeled XNP-CR or XNP-R with metal element concentrations of $50 \mu \mathrm{g} / \mathrm{mL}$. After incubation for $0,1,2,4$, and $8 \mathrm{~h}$, the cells were washed with PBS three times and stained with Lysotracker Green for 45 min. After cleaning with PBS, the cells were fixed with $4 \%$ paraformaldehyde solution for $20 \mathrm{~min}$. After washing cells with PBS again, DAPI was used to visualize the nuclei. After removing the free DAPI, the cells were observed by CLSM (Olympus FV1200, Japan).

(2) Quantitative analysis by ICP-MS: The U-87MG cells were seeded in 6-well plate $\left(2 \times 10^{5}\right.$ cells/ well). After $24 \mathrm{~h}$ incubation, the medium was replaced with $2 \mathrm{~mL}$ of fresh MEM containing XNP-CR or XNP-R with metal concentrations of $50 \mu \mathrm{g} / \mathrm{mL}$. After incubation for 1 , 2, 4, and $8 \mathrm{~h}$, the cells were trypsinized and digested with $1 \mathrm{~mL}$ of nitric acid. The Fe, Mn or Au content ingested by the cells was measured by ICP-MS. In addition, the cellular uptake of IONP-CR and IONP-R were also quantitatively analyzed using HeLa cells, A549 cells and L02 cells by ICP-MS.

(3) Quantitative flow cytometry analysis: The U-87MG cells were seeded in 6-well plate $\left(2 \times 10^{5}\right.$ cells/ well). After $24 \mathrm{~h}$ incubation, the medium was replaced with $2 \mathrm{~mL}$ of fresh MEM containing RITC-labeled XNP-CR or XNP-R with metal concentrations of $50 \mu \mathrm{g} / \mathrm{mL}$. After incubation for $1,2,4$, and $8 \mathrm{~h}$, the cells were trypsinized and resuspended with $300 \mu \mathrm{L}$ of PBS. 
The intensity of fluorescence was measured with flow cytometry (CytoFLEX LX, Beckman Coulter, USA).

(4) Bio-TEM: The U-87MG cells were cultured in cell dishes containing $10 \mathrm{~mL}$ of MEM supplement with $10 \%$ fetal bovine serum and incubated for $24 \mathrm{~h}$. XNP-CR $(50 \mu \mathrm{g}$ $[\mathrm{Fe} / \mathrm{Mn} / \mathrm{Au}] / \mathrm{mL}$ ) were added to the cells, respectively. After incubating for $4 \mathrm{~h}$, the cells were washed with PBS, centrifuged, and fixed with $2.5 \%$ glutaraldehyde. The cells were stained with osmium tetroxide, followed by thin sectioning and observation under TEM.

In vitro MR imaging and fluorescence imaging: U-87MG cells were cultured on cell dishes in $10 \mathrm{~mL}$ of MEM supplement with $10 \%$ fetal bovine serum. The cells were maintained in an atmosphere of $5 \% \mathrm{CO}_{2}$ and $95 \%$ humidified air at a constant temperature of $37^{\circ} \mathrm{C}$. After $24 \mathrm{~h}$ incubation, the medium was replaced with $5 \mathrm{~mL}$ of fresh MEM containing XNP-CR or XNP-R with metal element concentrations of 0,2 or $4 \mu \mathrm{g} / \mathrm{mL}$. After $4 \mathrm{~h}$, the cells were washed with PBS three times and trypsinized. After centrifugation, the cells were fixed with $1 \%$ agarose in $200 \mu \mathrm{L}$ test tube. The T2-weighted MR images of IONP-CR or IONP-R were obtained with a $9.0 \mathrm{~T}$ MRI scanner: TR $=2500 \mathrm{~ms}, \mathrm{TE}=30 \mathrm{~ms}$ and FOV $=45 \times 30 \mathrm{~mm}^{2}$. The T1-weighted MR images of MONP-CR and MONP-R were obtained with the 9.0 T MRI scanner: $\mathrm{TR}=500 \mathrm{~ms}, \mathrm{TE}=7.5 \mathrm{~ms}$ and $\mathrm{FOV}=40 \times 40 \mathrm{~mm}^{2}$. The fluorescence images of GNRCR and GNR-R were measured using a small animal imaging system (VISQUE In Vivo Elite, Korea) under the excitation/emission wavelengths of 565/578 nm.

Molecular dynamics (MD) simulations: The MD simulations were performed with Gromacs 5.0 and the molecular visualization can be achieved with visual molecular dynamics (VMD) graphics software. The structure of RGD-aCB and RGD-SP were calculated and 
optimized using Gaussian 09, and the GAFF forcefield parameters of them were formed using AmberTools. The Amber 99sb-ildn was used as the forcefield of integrin $\alpha_{v} \beta_{3}$. The simulation system was constructed in a box of $10 \times 10 \times 10 \mathrm{~nm}^{3}$. Integrin $\alpha_{v} \beta_{3}$ was set at the center of the box. RGD-aCB or RGD-SP was docked into the binding site of integrin $\alpha_{v} \beta_{3}$ using software AutoDock, according to the previously reported research. ${ }^{6}$ Then the simulation system was filled with water molecules. The temperature and pressure of the system were $310 \mathrm{~K}$ and 101 $\mathrm{kPa}$ respectively. The integration time step was set as 2 fs per step and the system was simulated under isothermal-isobaric ensemble. The simulation equilibrium time for each system was conducted for 10 ns. Finally, the electrostatic interactions were calculated according to Columb's law, and long-range electrostatic interactions were estimated via the particle mesh Ewald method. The Lorentz-Berthelot rule was used to calculate the Lennard-Jones potential for the cross interactions among non-bonded atoms.

Cytotoxicity: L02 cells were cultured on 96 -well plate $\left(1 \times 10^{4}\right.$ cells/ well) filled with DMEM supplement with $10 \%$ fetal bovine serum. The cells were maintained in an atmosphere of 5\% $\mathrm{CO}_{2}$ and $95 \%$ humidified air at a constant temperature of $37{ }^{\circ} \mathrm{C}$. After $24 \mathrm{~h}$ incubation, the medium was replaced with $200 \mu \mathrm{L}$ of fresh DMEM containing XNP-CR or XNP-R with metal element concentrations of $0,5,10,25,50,100$, and $150 \mu \mathrm{g} / \mathrm{mL}$. After $24 \mathrm{~h}$ treatment, the medium was replaced with $100 \mu \mathrm{L}$ of fresh DMEM containing $10 \mu \mathrm{L}$ of CCK 8 and measured on a microplate spectrophotometer (BioTek Instruments, USA).

In vivo MR imaging and fluorescence imaging: The animal experiments were performed with the approval of the Institutional Animal Care and Use Committee of Zhejiang University School of Medicine and followed the National Guidelines for Animal Protection. The 
subcutaneous xenotransplanted tumor model was established by subcutaneous injection of U87MG cells. When the diameter of the tumor grew to 4-6 mm, IONP-CR or IONP-R with a Fe concentration of $16 \mathrm{mg} / \mathrm{kg}$ were intravenously injected into the mice. The T2-weighted MR images were obtained with a 9.0 T MRI scanner: TR=2000 ms, TE=35 ms and FOV=45×45 $\mathrm{mm}^{2}$. The sensitivity of tumor detection was quantified based on the calculation of signal-tonoise ratio (SNR) before and after administration with nanoparticles: $\mathrm{SNR}_{\text {post }} / \mathrm{SNR}_{\text {pre. In }}$ addition, the T1-weighted MRI of MONP-CR and MONP-R were also evaluated with the 9.0 T MRI scanner $\left(\mathrm{TR}=350 \mathrm{~ms}, \mathrm{TE}=7.4 \mathrm{~ms}\right.$ and $\left.\mathrm{FOV}=45 \times 45 \mathrm{~mm}^{2)}\right)$, and the fluorescence imaging of RITC-labeled GNR-CR and GNR-R were assessed through a small animal imaging system (excitation/emission wavelengths: $565 / 578 \mathrm{~nm}$ ).

Pharmacokinetic analysis: $200 \mu \mathrm{L}$ of IONP-CR or IONP-R $(16 \mathrm{mg} / \mathrm{kg})$ was injected into balb/c mice via the tail vein respectively. After the injection, blood samples were collected at $1 \mathrm{~min}, 5 \mathrm{~min}, 15 \mathrm{~min}, 30 \mathrm{~min}, 1 \mathrm{~h}, 3 \mathrm{~h}$, and $24 \mathrm{~h} .20 \mu \mathrm{L}$ plasma of each sample was acquired by centrifugation and added into nitric acid to digest. The Fe content of samples was measured with ICP-MS after 10-fold dilution with $2 \%$ nitric acid.

Biodistribution: The tumor-bearing mice were injected with IONP-CR or IONP-R (16 $\mathrm{mg} / \mathrm{kg}$ ) via the tail vein respectively. After $3 \mathrm{~h}$ post-injection, the mice were sacrificed and the main organs (including heart, kidney, liver, lung and spleen) and tumor tissues were weighted and added into $1 \mathrm{~mL}$ of nitric acid to digest. The Fe content of samples was measured with ICP-MS after 10-fold dilution with $2 \%$ nitric acid.

In vivo toxicity evaluation: $200 \mu \mathrm{L}$ of IONP-CR $(16 \mathrm{mg} / \mathrm{kg})$ or saline was injected into $\mathrm{balb} / \mathrm{c}$ mice via the tail vein respectively. After 1 day or 15 days, the blood samples were 
collected and the mice were sacrificed. The serum was collected by centrifugation to evaluate the liver function (including ALP, ALT, AST, TP, ALB, GLOB and A/G) and kidney function (including BUN and CREA). The whole blood was used to assess the hematological indices (including $\mathrm{WBC}, \mathrm{RBC}, \mathrm{HGB}, \mathrm{HCT}, \mathrm{MCH}, \mathrm{MCHC}, \mathrm{MCV}$, and PLT). The main organs including heart, kidney, liver, lung and spleen were acquired and stained with hematoxylin \& $\operatorname{eosin}(\mathrm{H} \& \mathrm{E})$. 


\section{Supporting Figures}
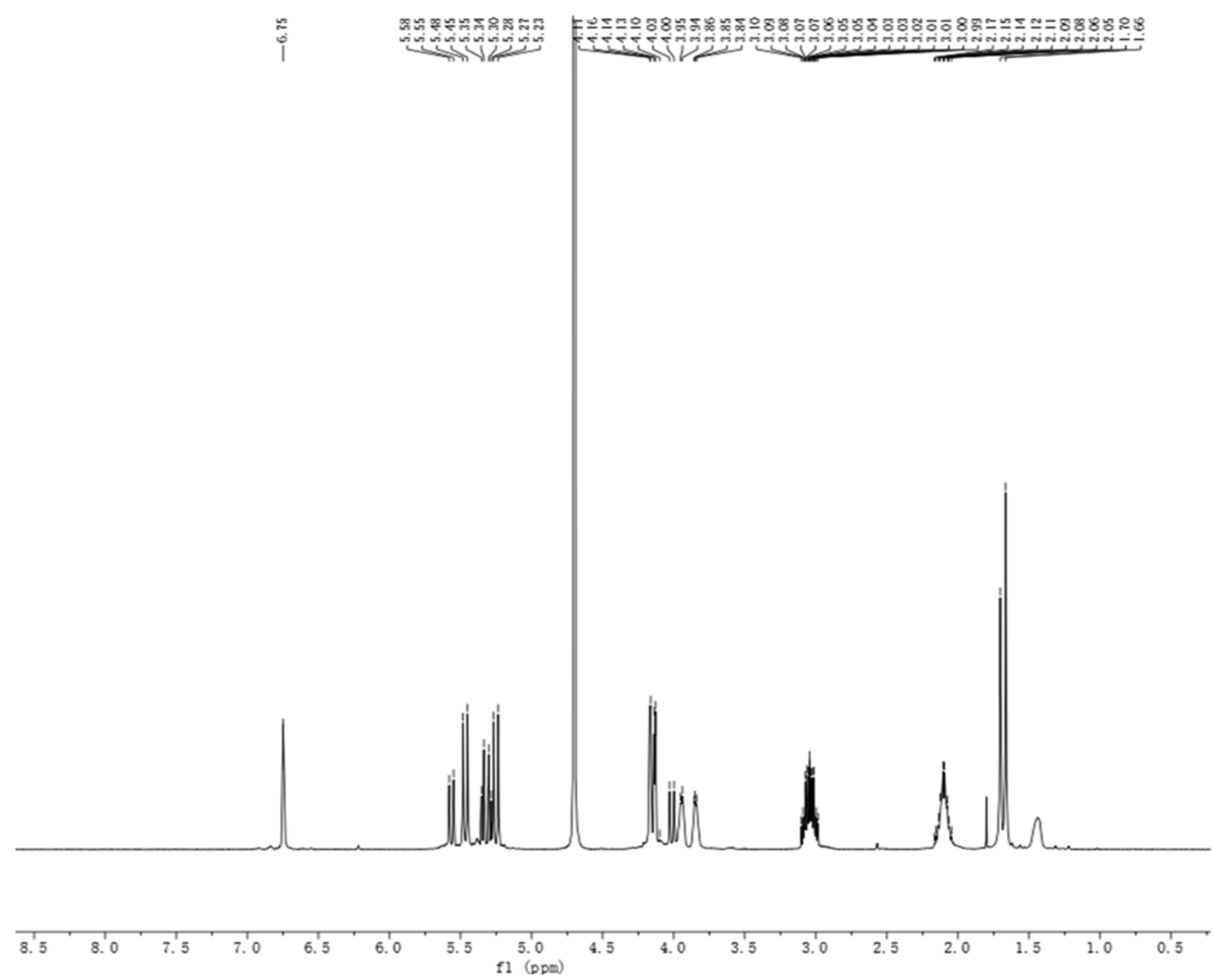

Figure S1. ${ }^{1} \mathrm{H}$ NMR spectrum $\left(500 \mathrm{MHz}, \mathrm{D}_{2} \mathrm{O}\right)$ recorded for aCB congener 1 .
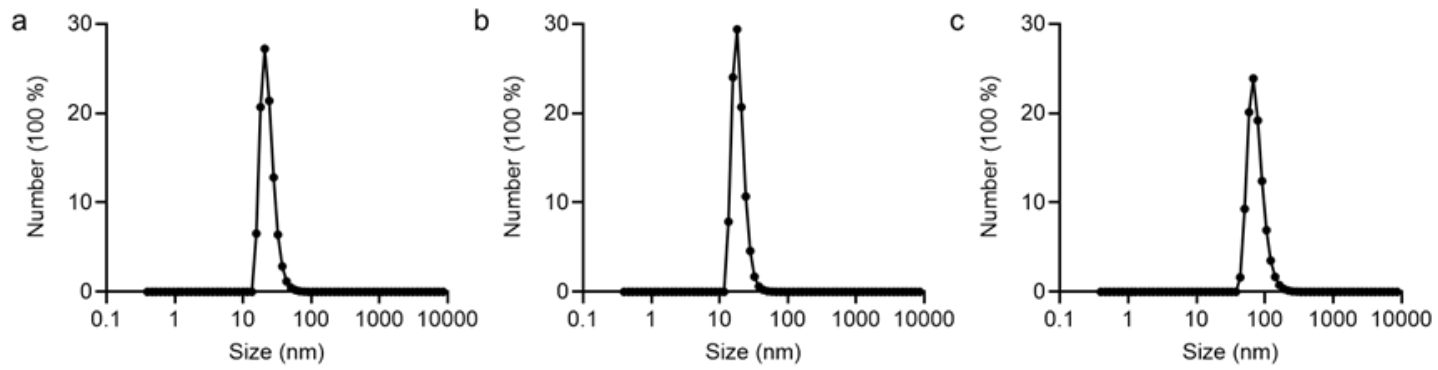

Figure S2. Hydrodynamic sizes of a) IONP-aCB, b) MONP-aCB, and c) GNR-aCB. 

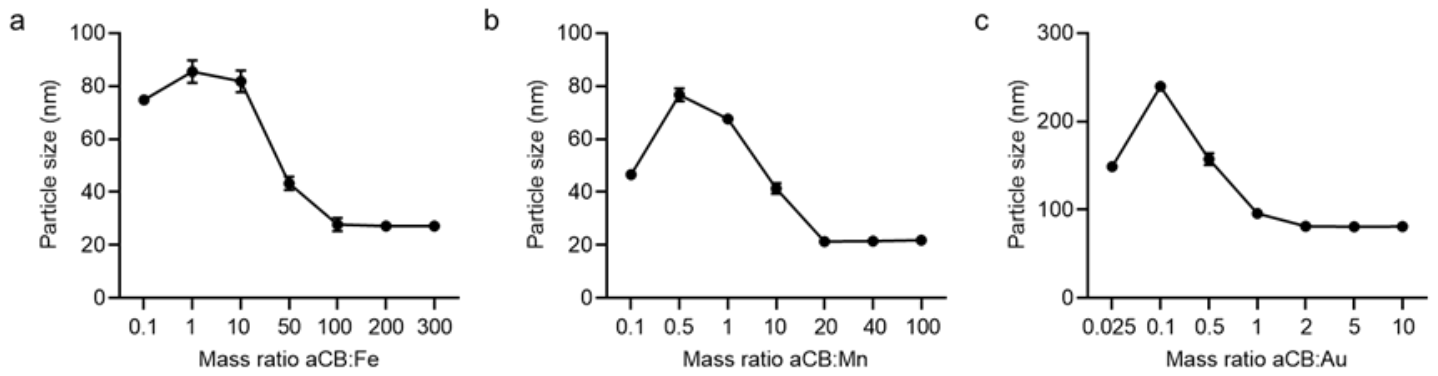

Figure S3. Exploration of preparation conditions of XNP-aCB. DLS measurement data at different mass ratios of aCB to metal element of XNP-SP. At low aCB: $\mathrm{Fe} / \mathrm{Mn} / \mathrm{Au}$ ratio, $\mathrm{aCB}$ would induce the aggregation of nanoparticles; When the $\mathrm{aCB}$ molecules are excess, the nanoparticles can be completely with $\mathrm{aCB}$ and the strong repulsive interaction prevents their aggregation.
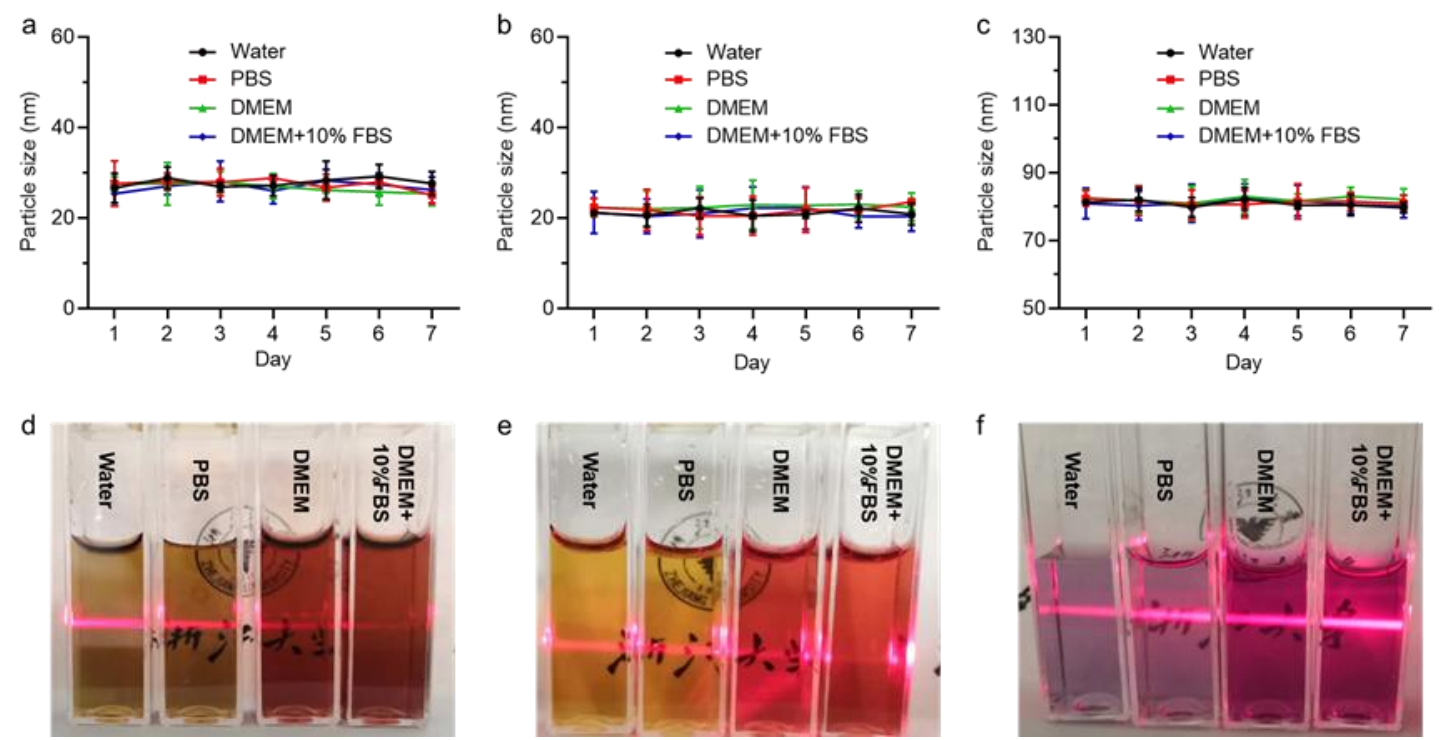

Figure S4. Colloidal stability analysis of XNP-CR. Hydrodynamic sizes of a) IONPCR, b) MONP-CR and c) GNR-CR in water, PBS, DMEM and DMEM containing 10\% FBS within one week. Tyndall effect of d) IONP-CR, e) MONP-CR and f) GNR-CR after incubation in different solutions for one week. 


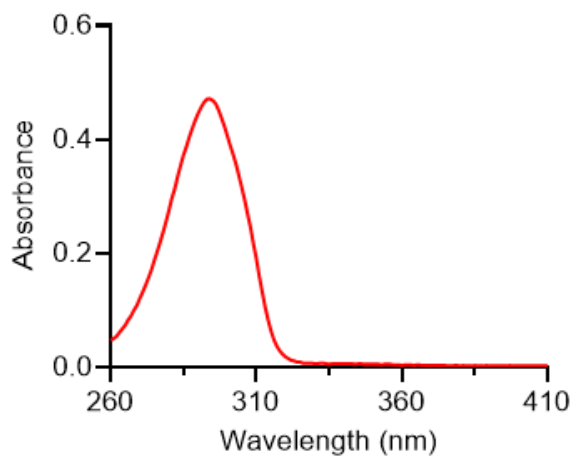

Figure S5. UV spectrum of aCB molecular container.

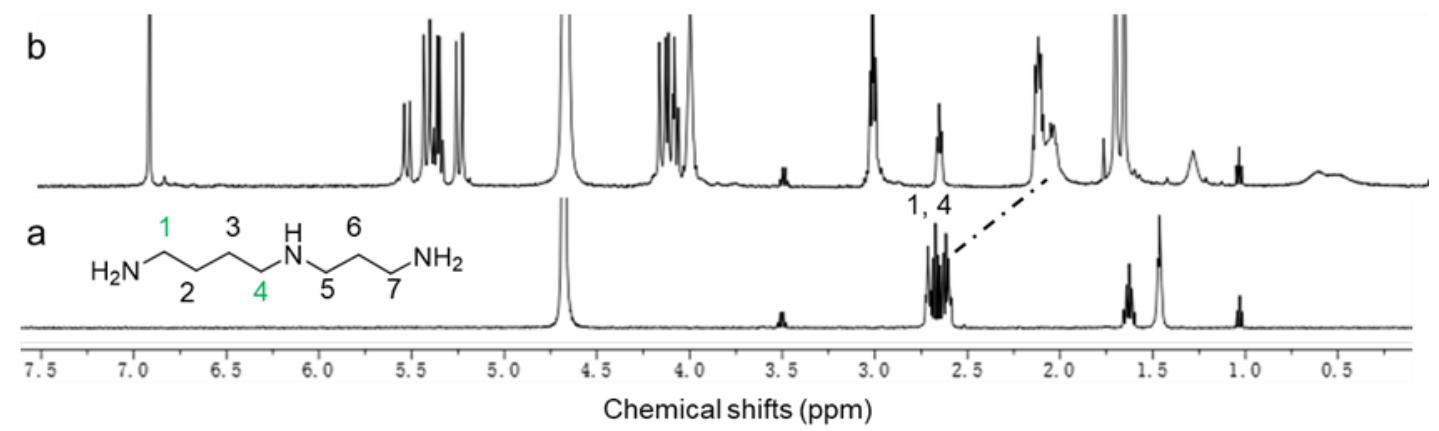

Figure S6. ${ }^{1} \mathrm{H}$ NMR spectra (500 MHz, $\left.\mathrm{D}_{2} \mathrm{O}\right)$ of a) spermidine, and b) aCB-spermidine complex.

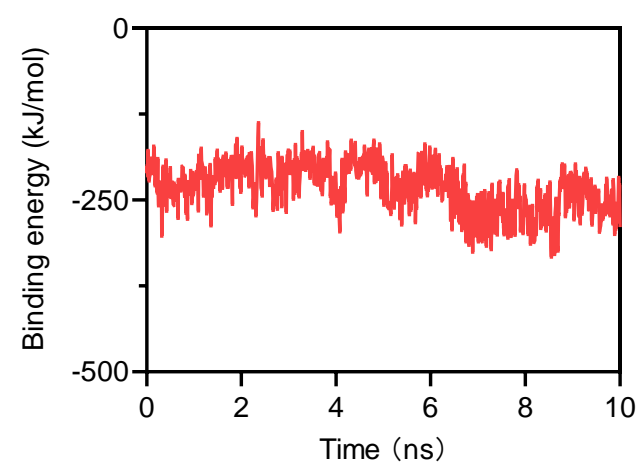

Figure S7. The binding energy between $\mathrm{aCB}$ and RGD-SP. 

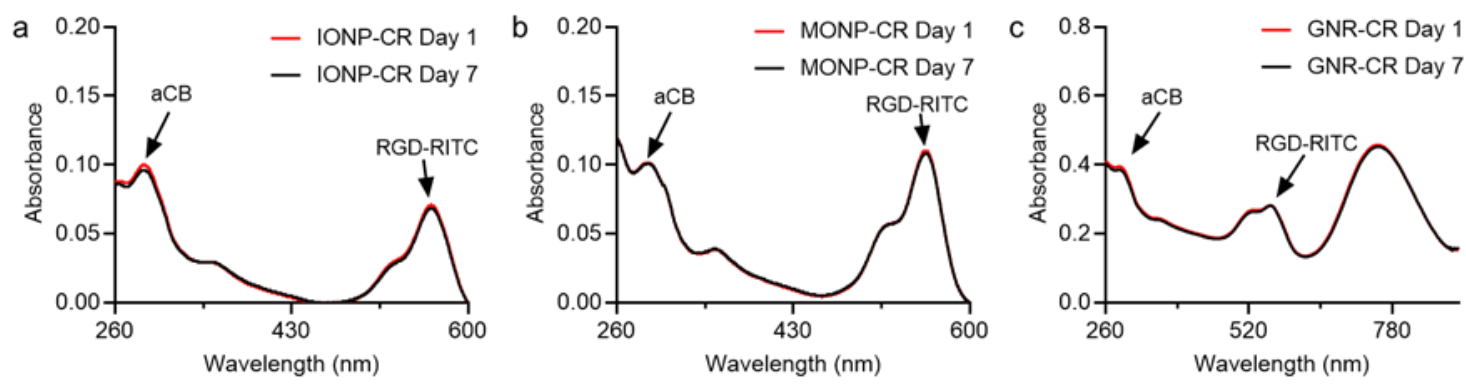

Figure S8. Structural stability analysis of XNP-CR. UV-Vis spectra of XNP-CR before and after incubation in PBS solution for one week. The absorption peaks of aCB and RGD-RITC did not decrease significantly after one week, indicating that RGD and aCB would not release from XNP-CR and the complexes have the ability to maintain their structure intact.
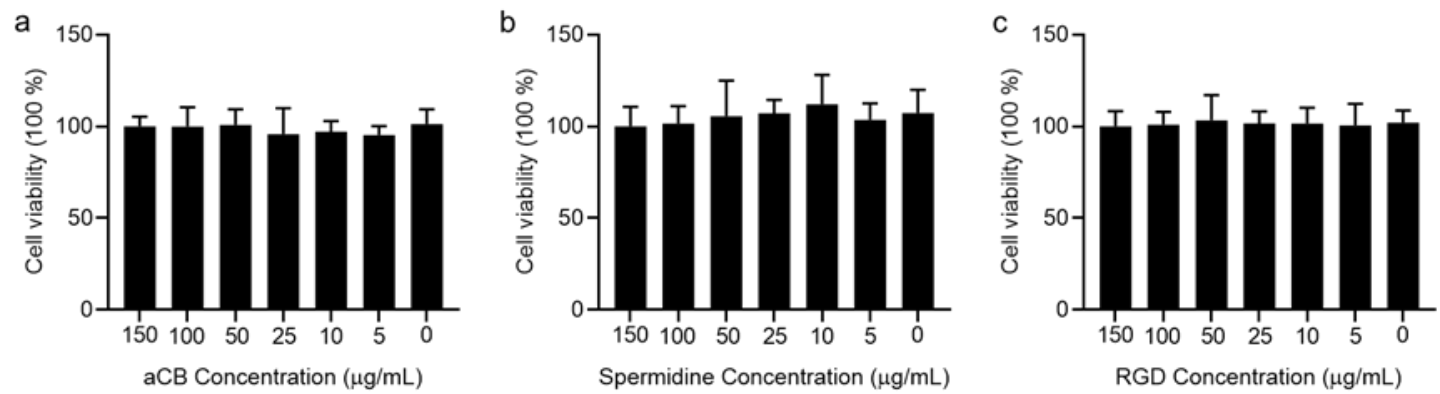

Figure S9. Cytotoxicity of aCB, spermidine, and RGD.
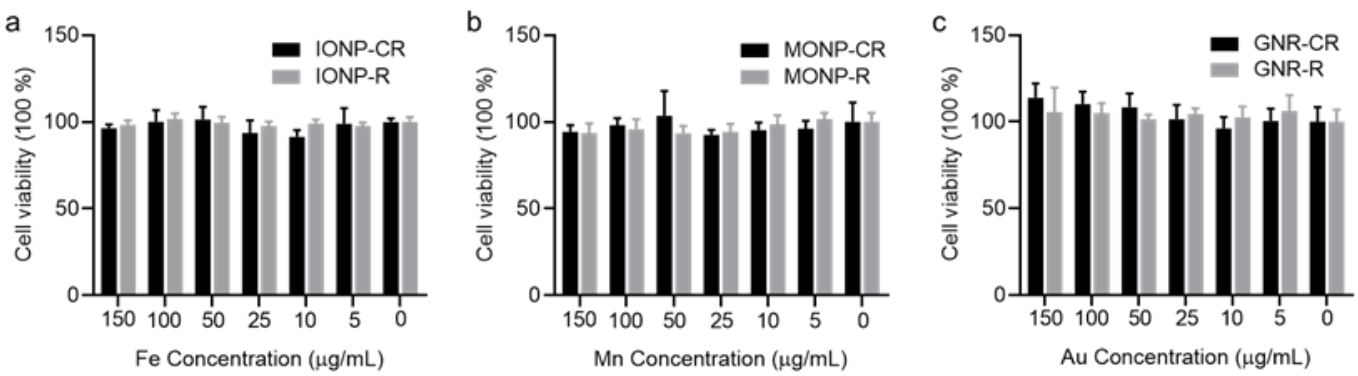

Figure S10. Cytotoxicity of XNP-CR and XNP-R. 

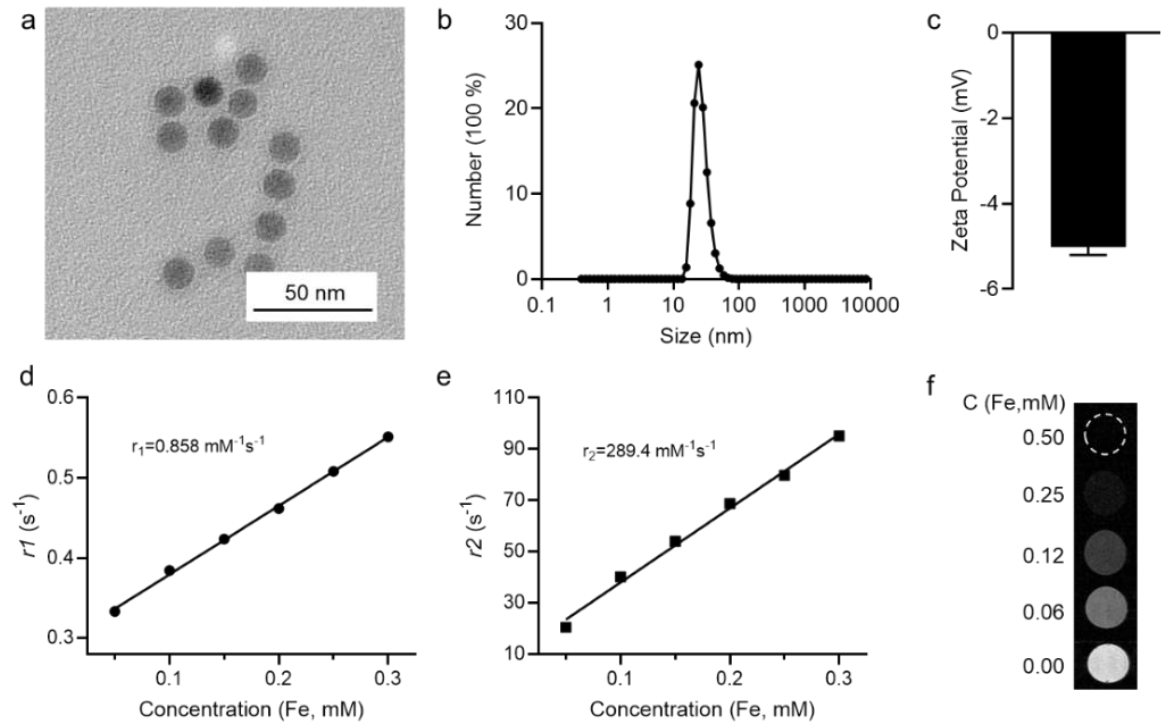

Figure S11. Characterization of IONP-R. a) TEM image, b) hydrodynamic size, c) zeta potential, d) r1 and e) r2 relaxivities, f) T2-weighted phantoms of IONP-R. The T2weighted phantoms of IONP-R get darker with the increase of Fe concentration. The r2 relaxivity and T2-weighted phantoms indicate that IONP-R can be used as T2 MR contrast agents.
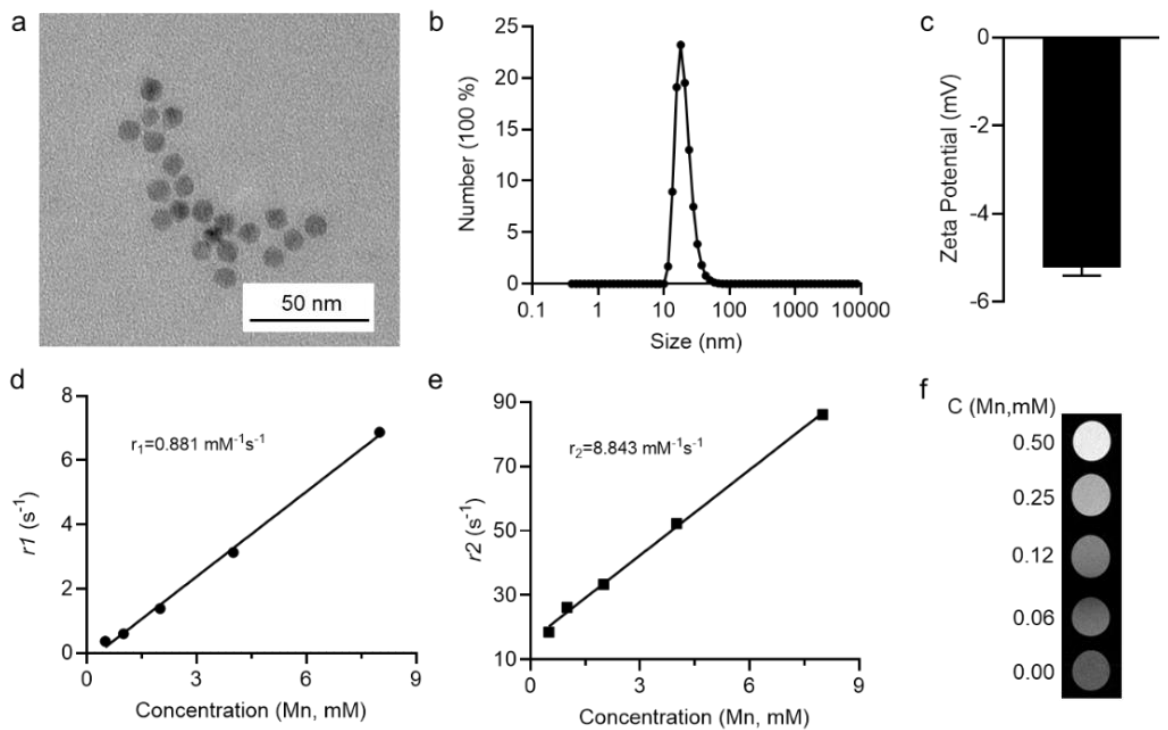

Figure S12. Characterization of MONP-R. a) TEM image, b) hydrodynamic size, c) zeta potential, d) r1 and e) r2 relaxivities, f) T1-weighted phantoms of MONP-R. The 
T1-weighted phantoms of MONP-R get brighter with the increase of Mn concentration. The $\mathrm{r} 2 / \mathrm{r} 1$ ratio and T1-weighted phantoms indicate that MONP-R can be used as T1 MR contrast agents.
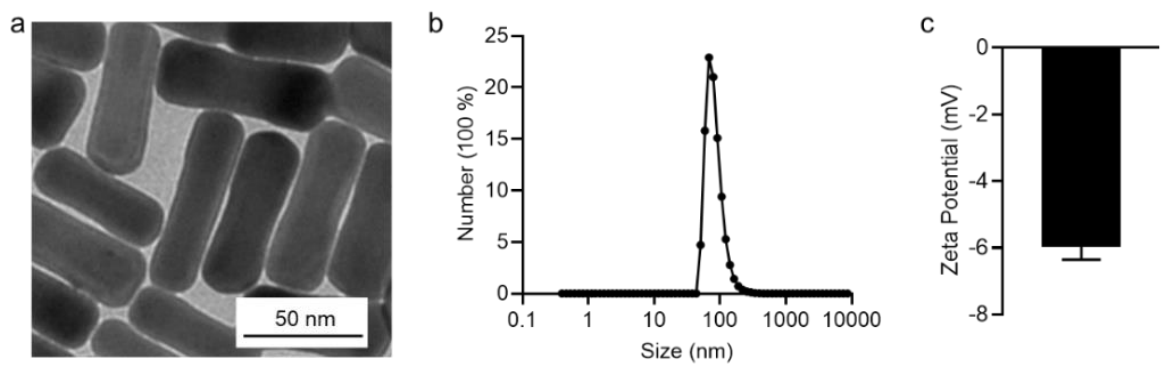

Figure S13. Characterization of GNR-R. a) TEM image, b) hydrodynamic size, and c) zeta potential of GNR-R.
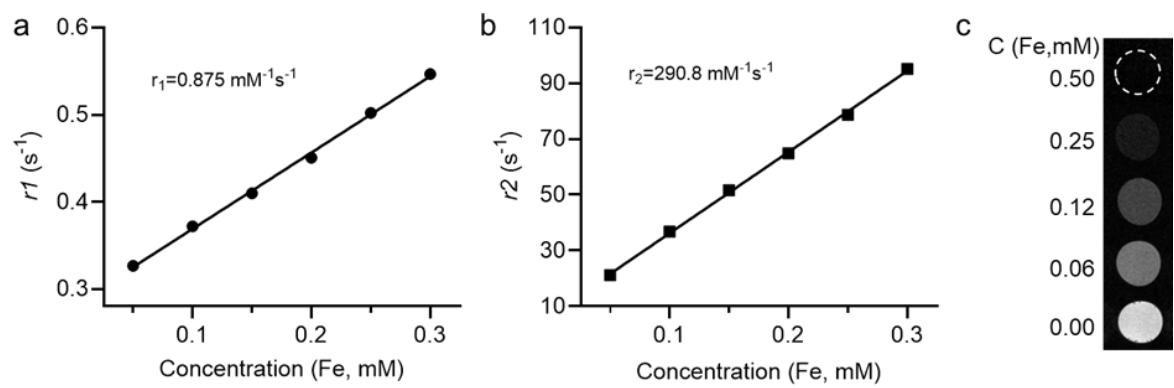

Figure S14. a) r1 and b) r2 relaxivities, c) T2-weighted phantoms of IONP-CR. The T2-weighted phantoms of IONP-CR get darker with the increase of Fe concentration. The $\mathrm{r} 2$ relaxivity and T2-weighted phantoms indicate that IONP-CR can be used as T2 MR contrast agents. In addition, IONP-CR and IONP-R possess similar MR properties. 

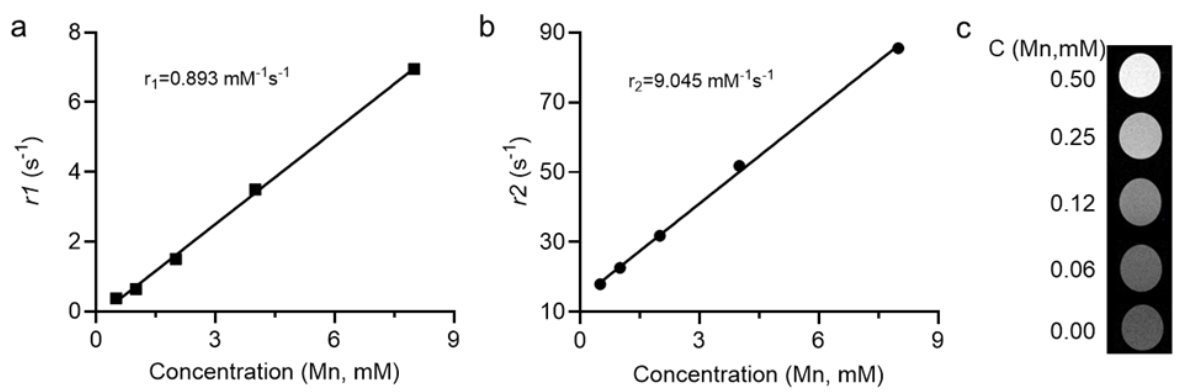

Figure S15. a) r1 and b) r2 relaxivities, c) T1-weighted phantoms of MONP-CR. The T1-weighted phantoms of MONP-R get brighter with the increase of Mn concentration. The $\mathrm{r} 2 / \mathrm{r} 1$ ratio and T1-weighted phantoms indicate that MONP-R can be used as T1 MR contrast agents. In addition, MONP-CR and MONP-R possess similar MR properties.
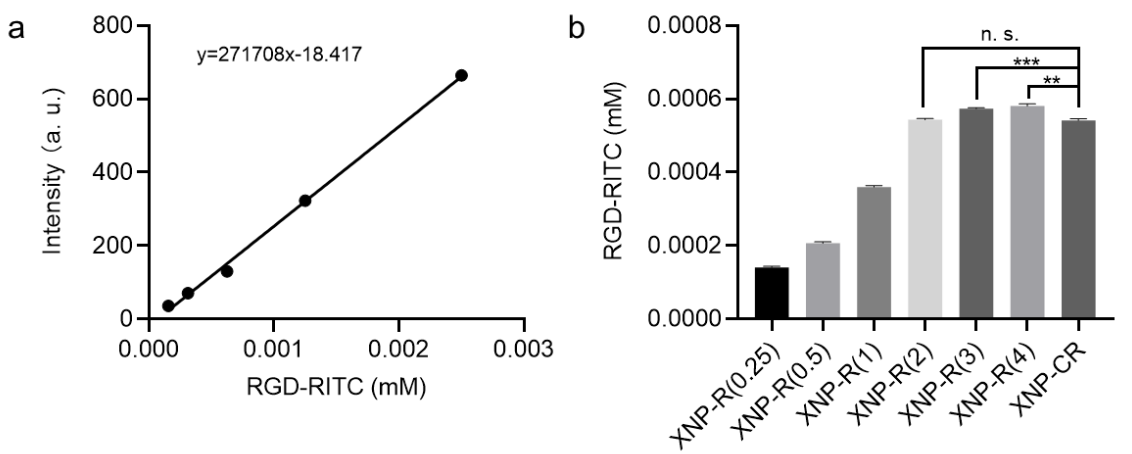

Figure S16. a) Fluorescence emission standard curve of RGD-RITC at $585 \mathrm{~nm}$ (excitation wavelength at $545 \mathrm{~nm}$ ). b) The amount of RGD modified onto XNP-R and XNP-CR. The molar ratio of RGD added to synthesize XNP-R and XNP-CR is 0.25, $0.5,1,2,3$ and 4 , respectively. When the RGD molar ratio is 2 , the amount of RGD modified onto the two nanoparticles are the same. Statistical analysis was performed using a one-way analysis of variance test, with $\mathrm{n}$. s. indicating no significance, $* * *$ indicating $p<0.001$ and $* *$ indicating $p<0.01(\mathrm{n}=3)$. 
IONP.CR

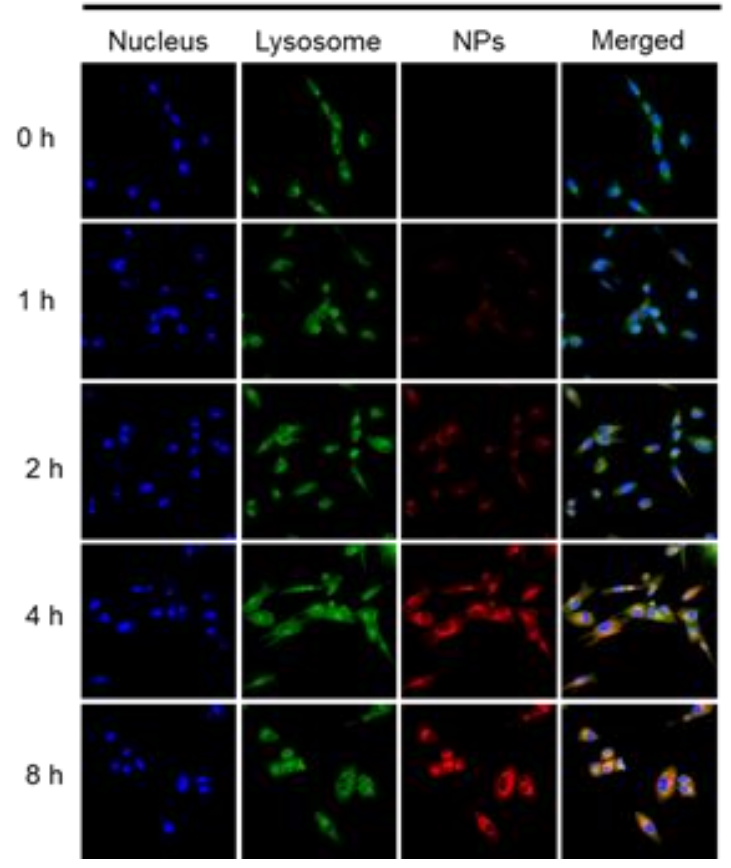

IONP-R

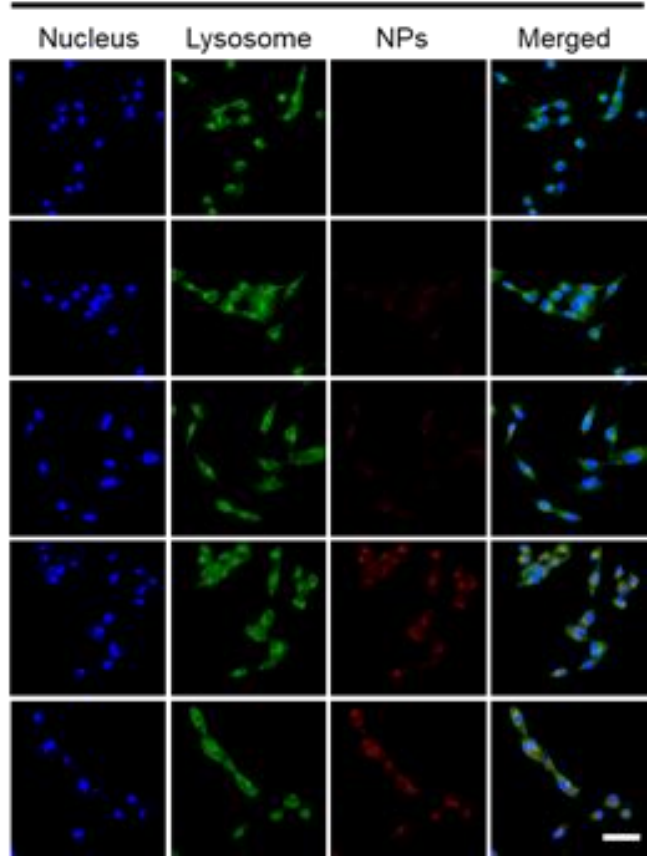

Figure S17. CLSM images of U-87MG cells after different incubation time of IONP-

$\mathrm{CR}$ and IONP-R $($ Scale bar $=50 \mu \mathrm{m})$.

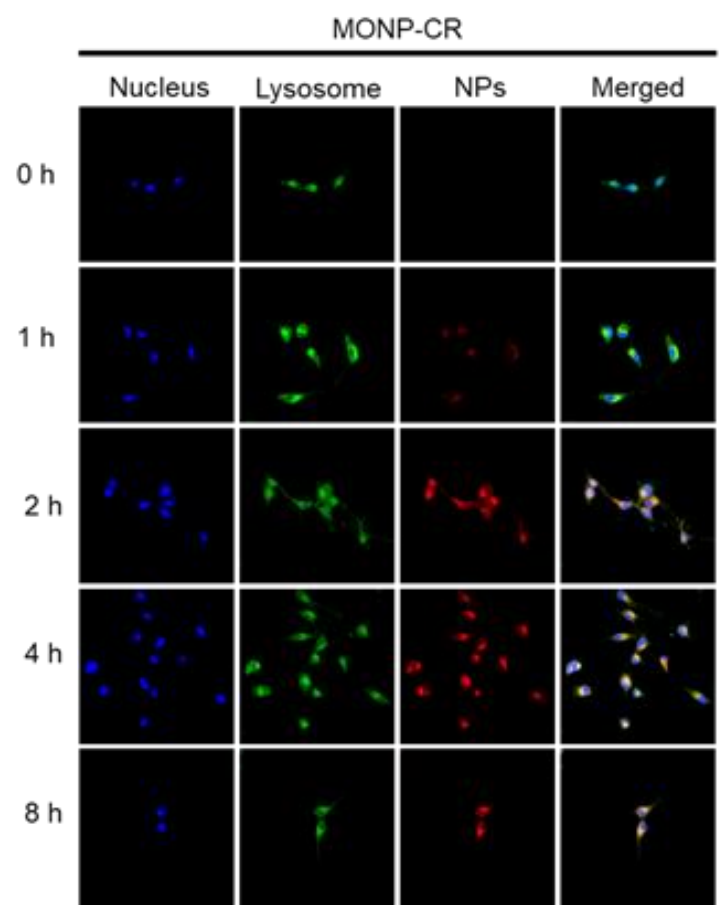

MONP-R

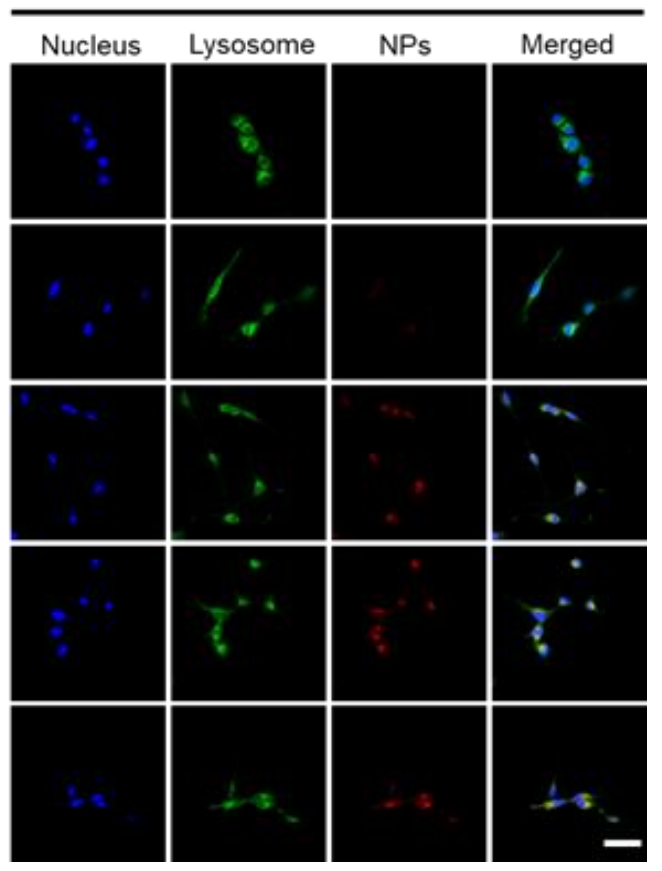

Figure S18. CLSM images of U-87MG cells after different incubation time of MONP-

$\mathrm{CR}$ and MONP-R $($ Scale bar $=50 \mu \mathrm{m})$. 


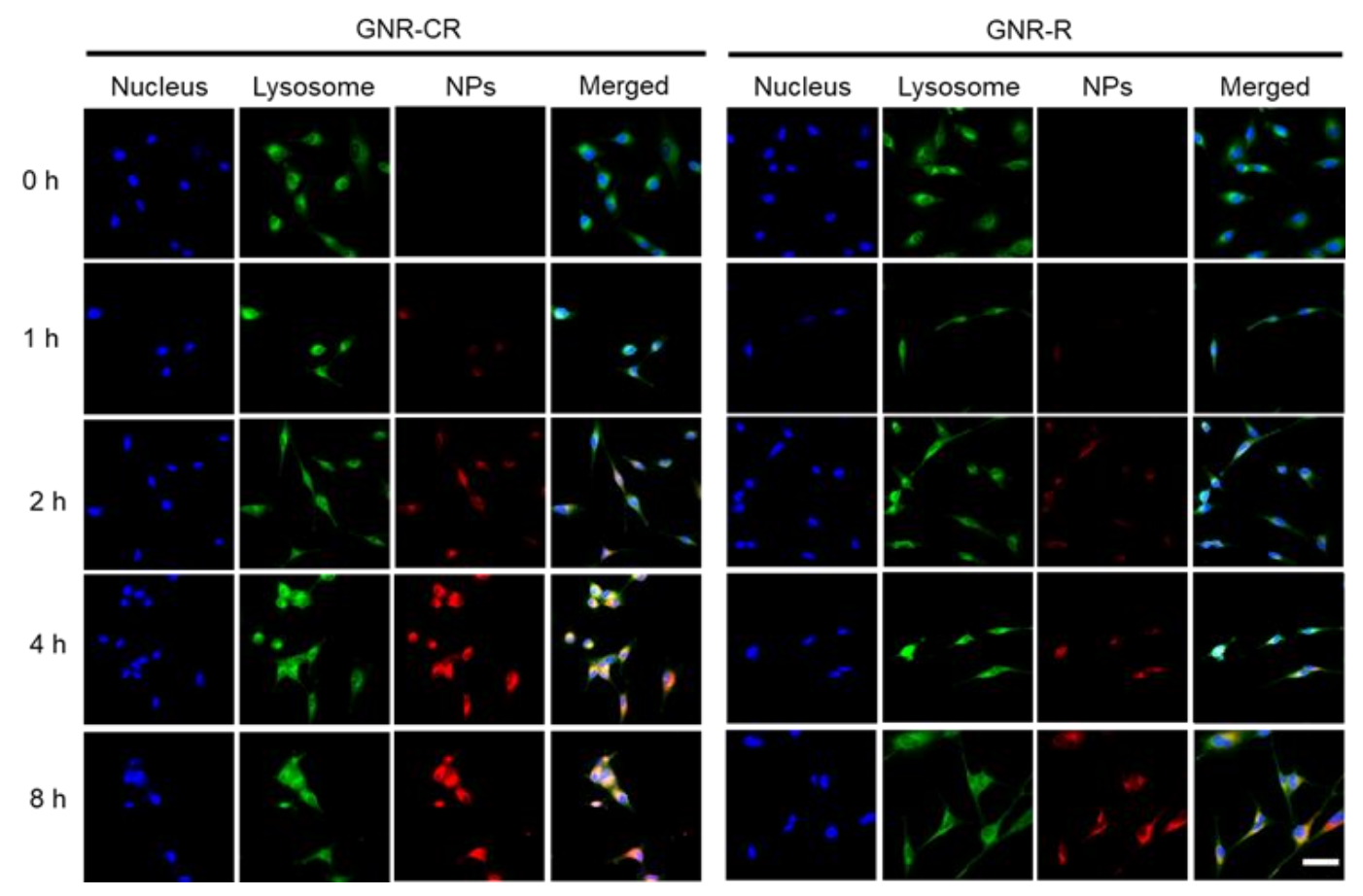

Figure S19. CLSM images of U-87MG cells after different incubation time of GNR-

CR and GNR-R (Scale bar $=50 \mu \mathrm{m})$.
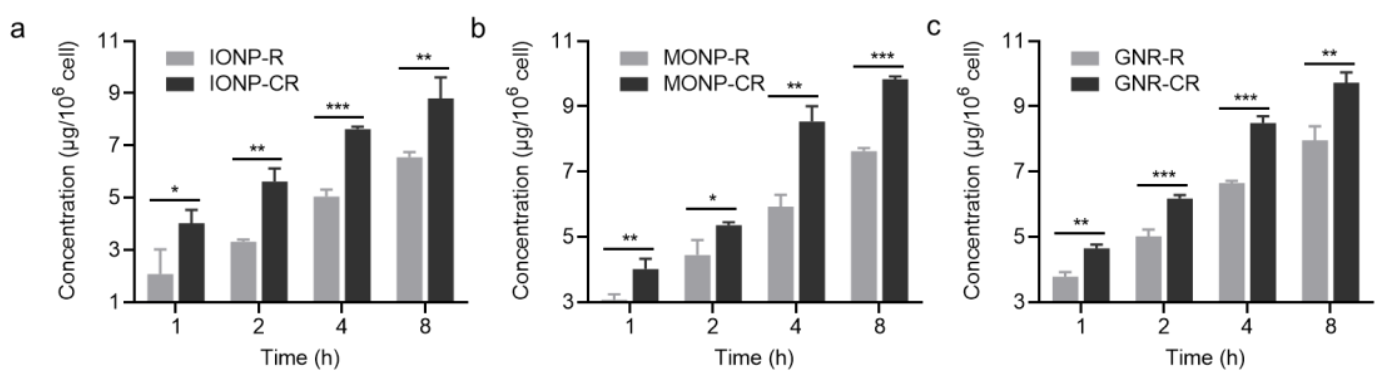

Figure S20. The cellular uptake of XNP-CR and XNP-R by U-87MG cells were measured via ICP-MS. Statistical analysis was performed using a one-way analysis of variance test, with $* * *$ indicating $p<0.001, * *$ indicating $p<0.01$ and $*$ indicating $p$ $<0.05(\mathrm{n}=3)$. 

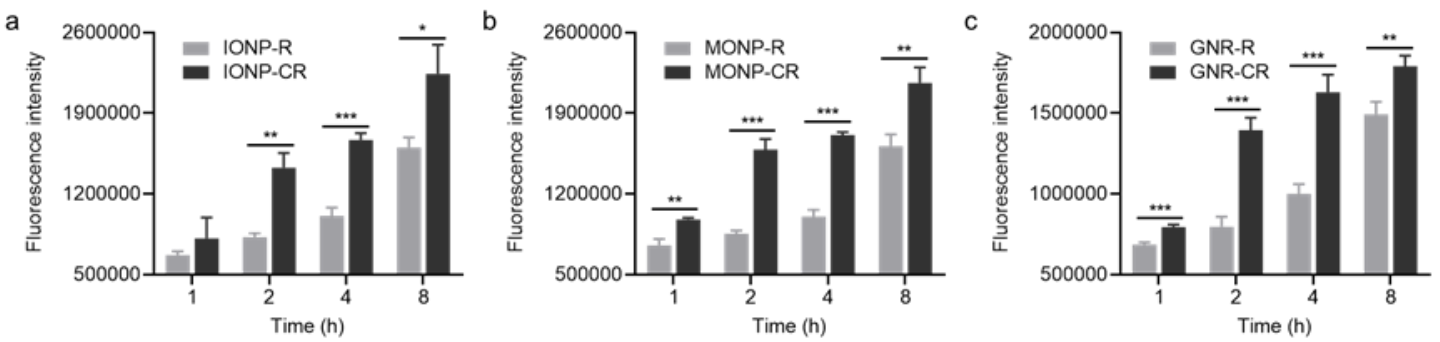

Figure S21. The cellular uptake of XNP-CR and XNP-R uptake by U-87MG cells were measured with flow cytometry. Statistical analysis was performed using a one-way analysis of variance test, with $* * *$ indicating $p<0.001, * *$ indicating $p<0.01$ and $*$ indicating $p<0.05(\mathrm{n}=3)$.
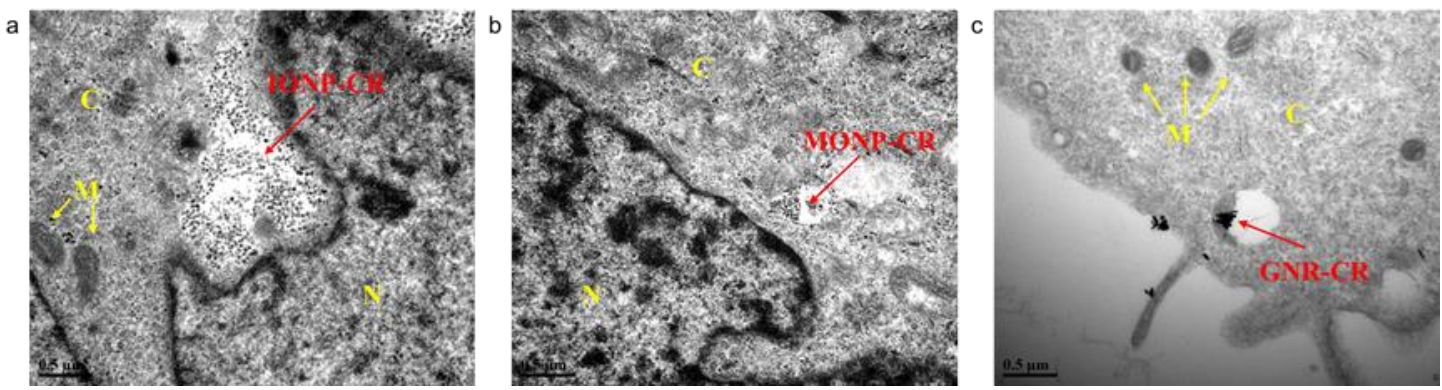

Figure S22. Representative TEM images of U-87MG cells after incubation with XNP-

CR. N: nucleus, M: mitochondria, C: cytoplasm.

a

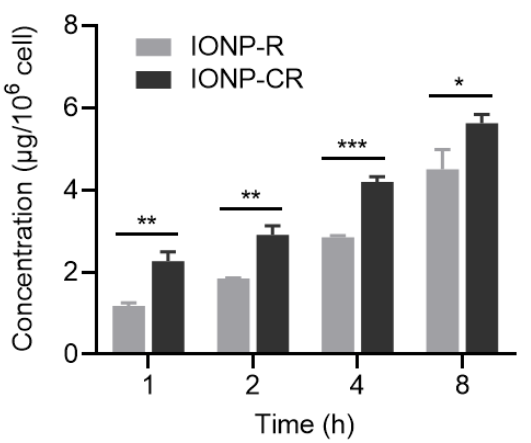

b

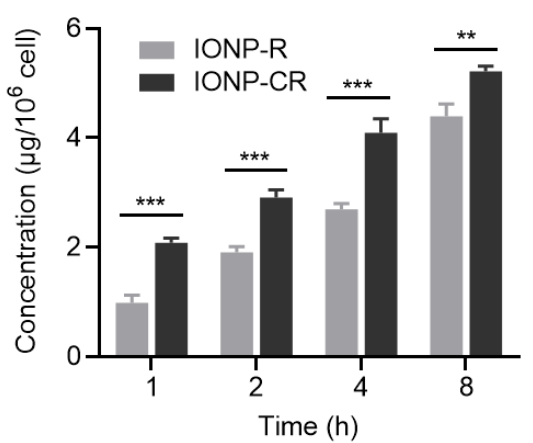

Figure S23. IONP-CR and IONP-R uptake in a) HeLa and b) A549 cells were measured by ICP-MS. Statistical analysis was performed using a one-way analysis of variance 
test, with *** indicating $p<0.001, * *$ indicating $p<0.01$ and $*$ indicating $p<0.05$ (n $=3)$.

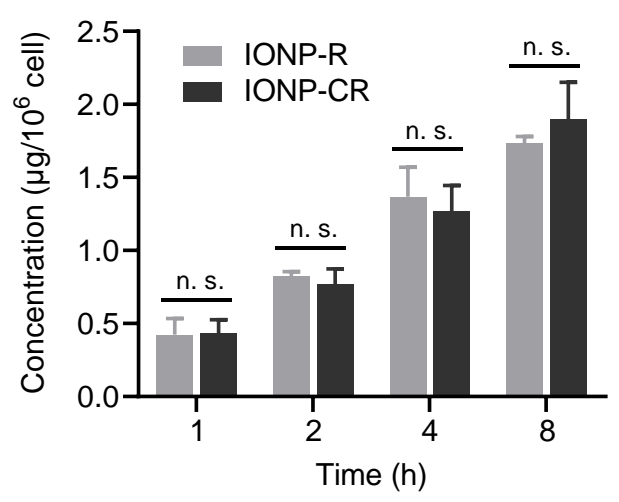

Figure S24. IONP-CR and IONP-R uptake in L02 cells were measured by ICP-MS.

Statistical analysis was performed using a one-way analysis of variance test, with $\mathrm{n}$. s. indicating no significance $(\mathrm{n}=3)$.

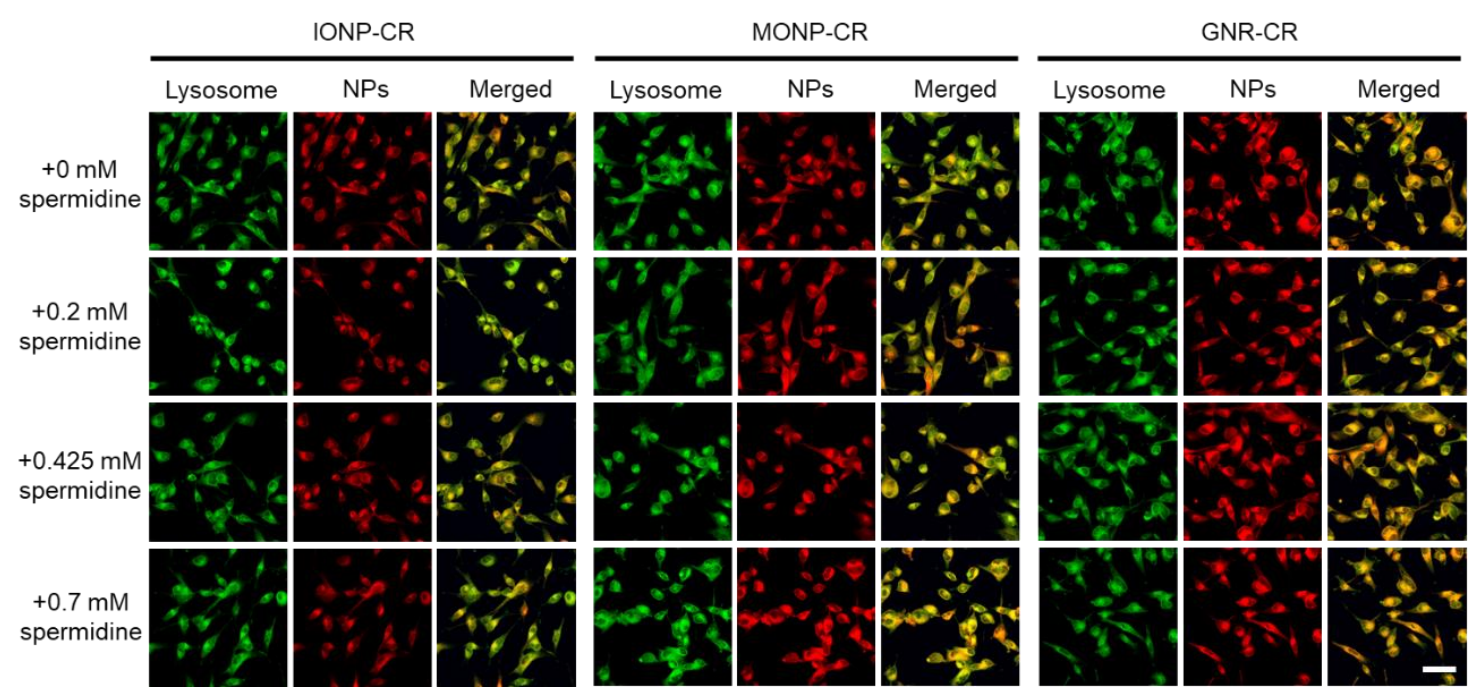

Figure S25. CLSM images of U-87MG cells incubated with XNP-CR and different concentrations of spermidine for $4 \mathrm{~h}($ Scale bar $=50 \mu \mathrm{m})$. 

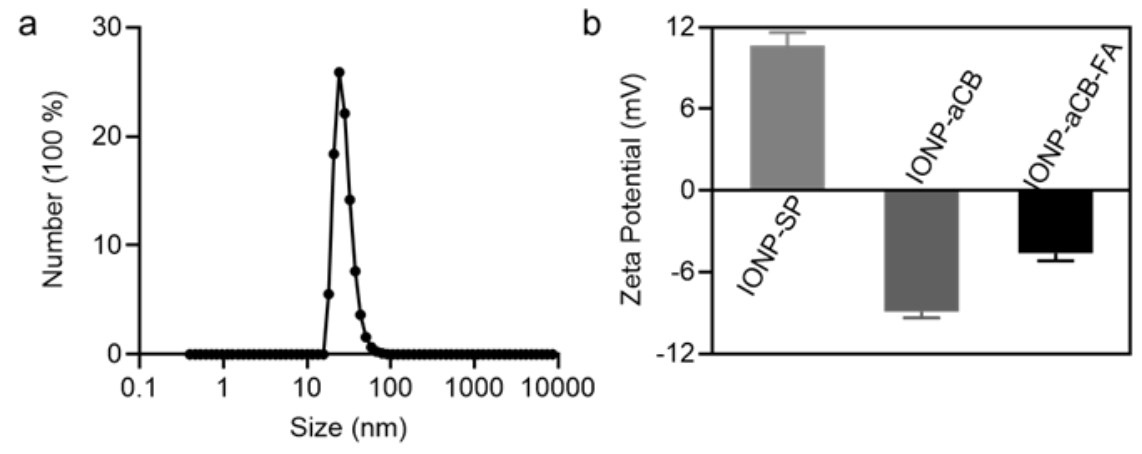

Figure S26. Characterization of IONP-aCB-FA. a) Hydrodynamic size of IONP-aCB-

FA. b) Zeta potential of nanoparticles before and after surface engineering.
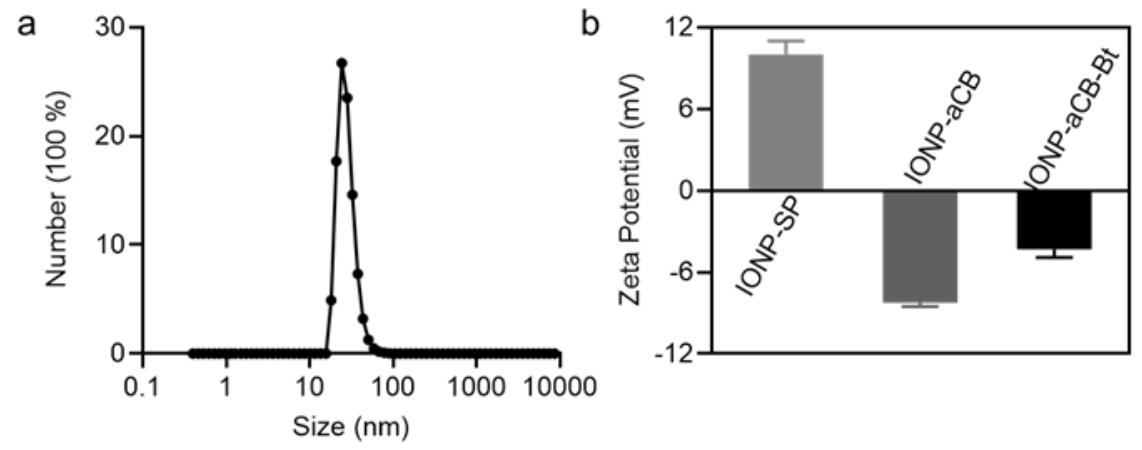

Figure S27. Characterization of IONP-aCB-Bt. a) Hydrodynamic size of IONP-aCBBt. b) Zeta potential of nanoparticles before and after surface engineering. 


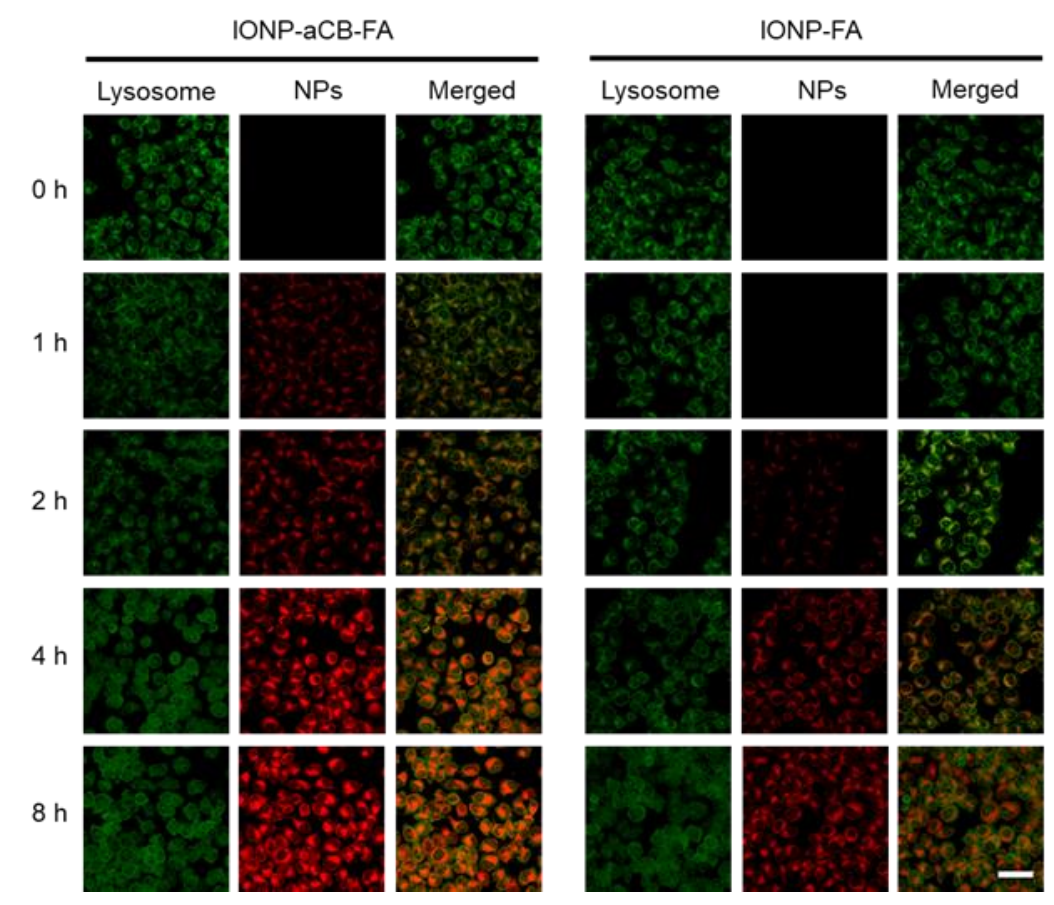

Figure S28. CLSM images of HeLa cells after incubation with IONP-aCB-FA and IONP-FA for different time (Scale bar $=50 \mu \mathrm{m})$.

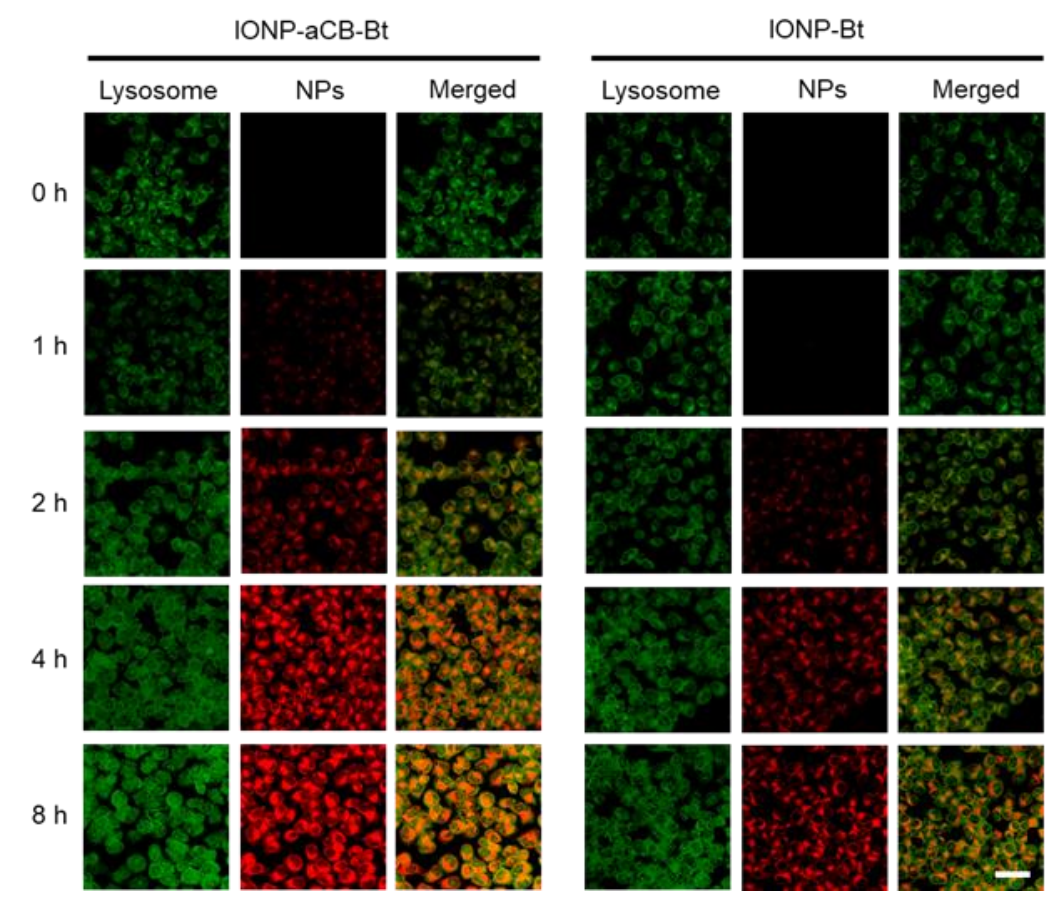

Figure S29. CLSM images of HeLa cells after incubation with IONP-aCB-Bt and IONP-Bt for different time (Scale bar $=50 \mu \mathrm{m})$. 

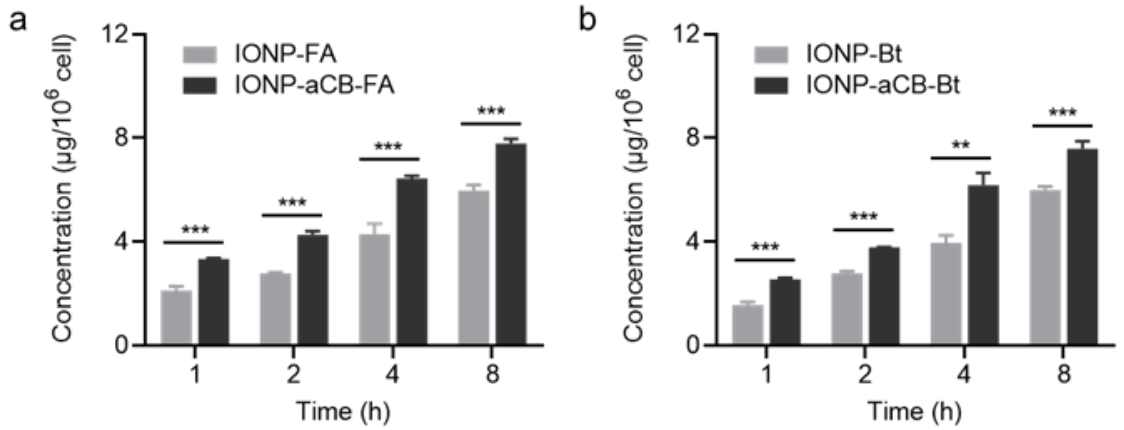

Figure S30. Quantitative analysis of cellular uptake of a) IONP-aCB-FA and IONP-FA,

b) IONP-aCB-Bt and IONP-Bt by ICP-MS. Statistical analysis was performed using a one-way analysis of variance test, with $* * *$ indicating $p<0.001$, and $* *$ indicating $p<$ $0.01(\mathrm{n}=3)$.

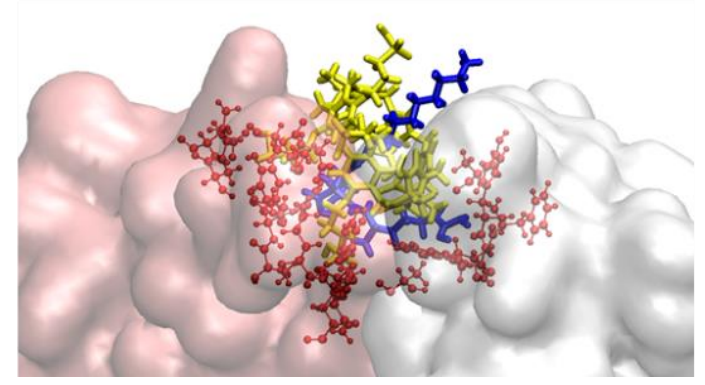

b

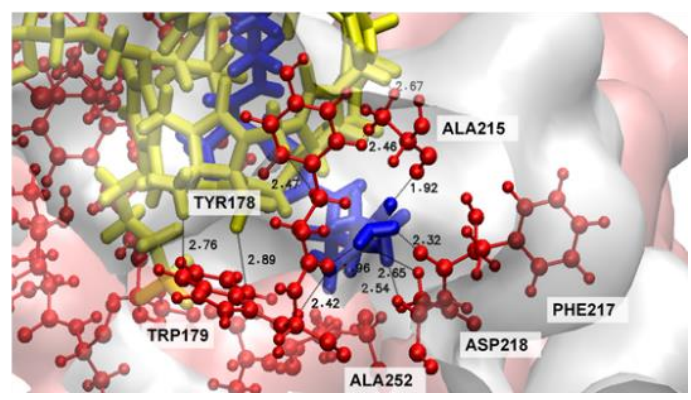

Figure S31. a) Binding sites and b) partial enlargement of aCB-RGD on integrin $\alpha_{v} \beta_{3}$.

a

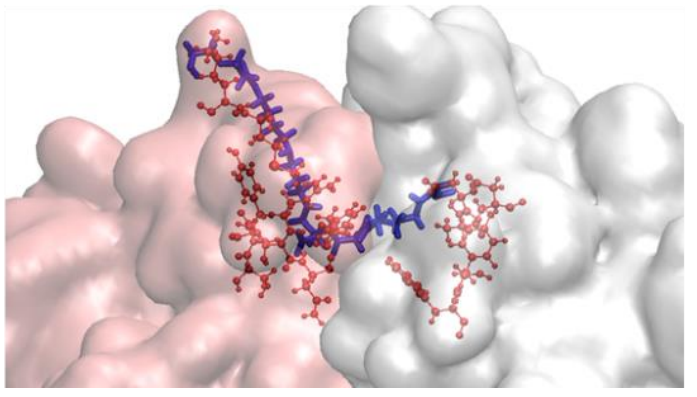

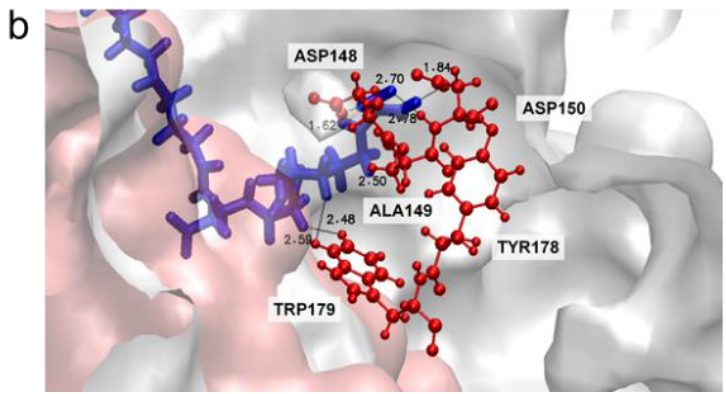

Figure S32. a) Binding sites and b) partial enlargement of linear RGD on integrin $\alpha_{v} \beta_{3}$. 

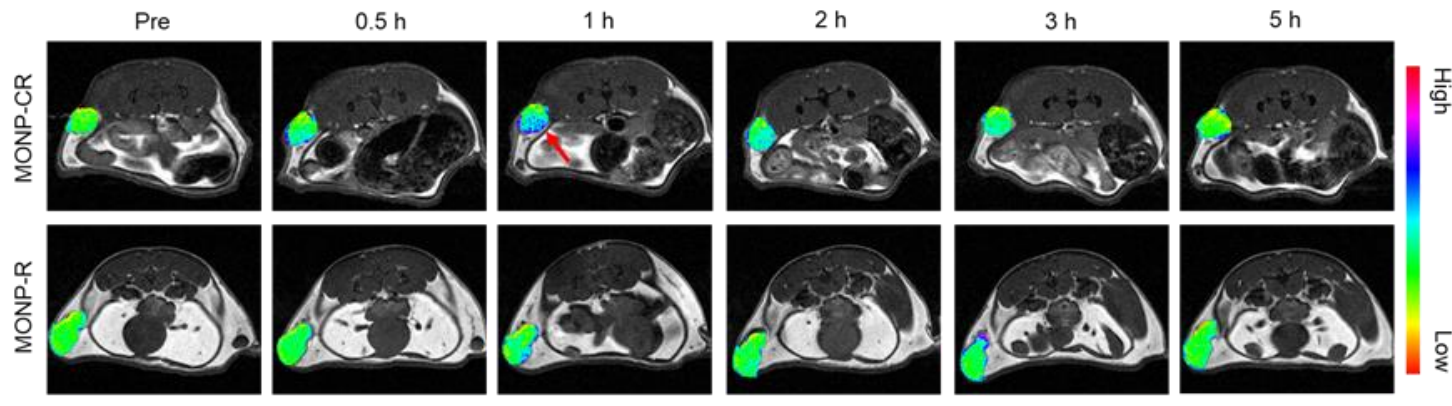

Figure S33. T1-weighted MR images of tumor-bearing nude mice after i.v. injection of

MONP-CR and MONP-R.

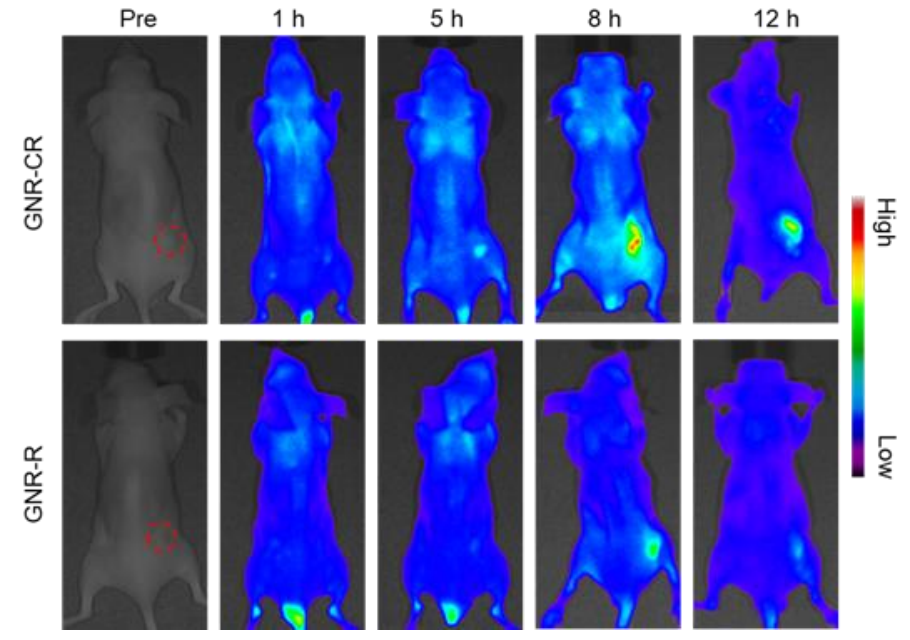

Figure S34. Fluorescence images of tumor-bearing nude mice after i.v. injection of RITC-labeled GNR-CR and GNR-R.

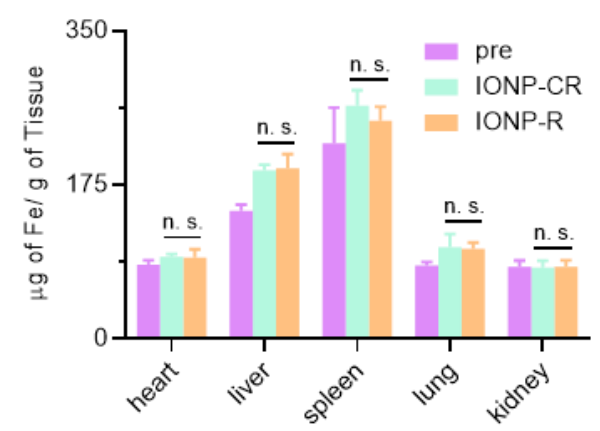

Figure S35. In vivo biodistribution of $\mathrm{Fe}$ at $3 \mathrm{~h}$ post-injection of IONP-CR and IONP-

R into tumor-bearing mice. Statistical analysis was performed using a one-way analysis 
of variance test, with n. s. indicating no significance $(n=3)$.
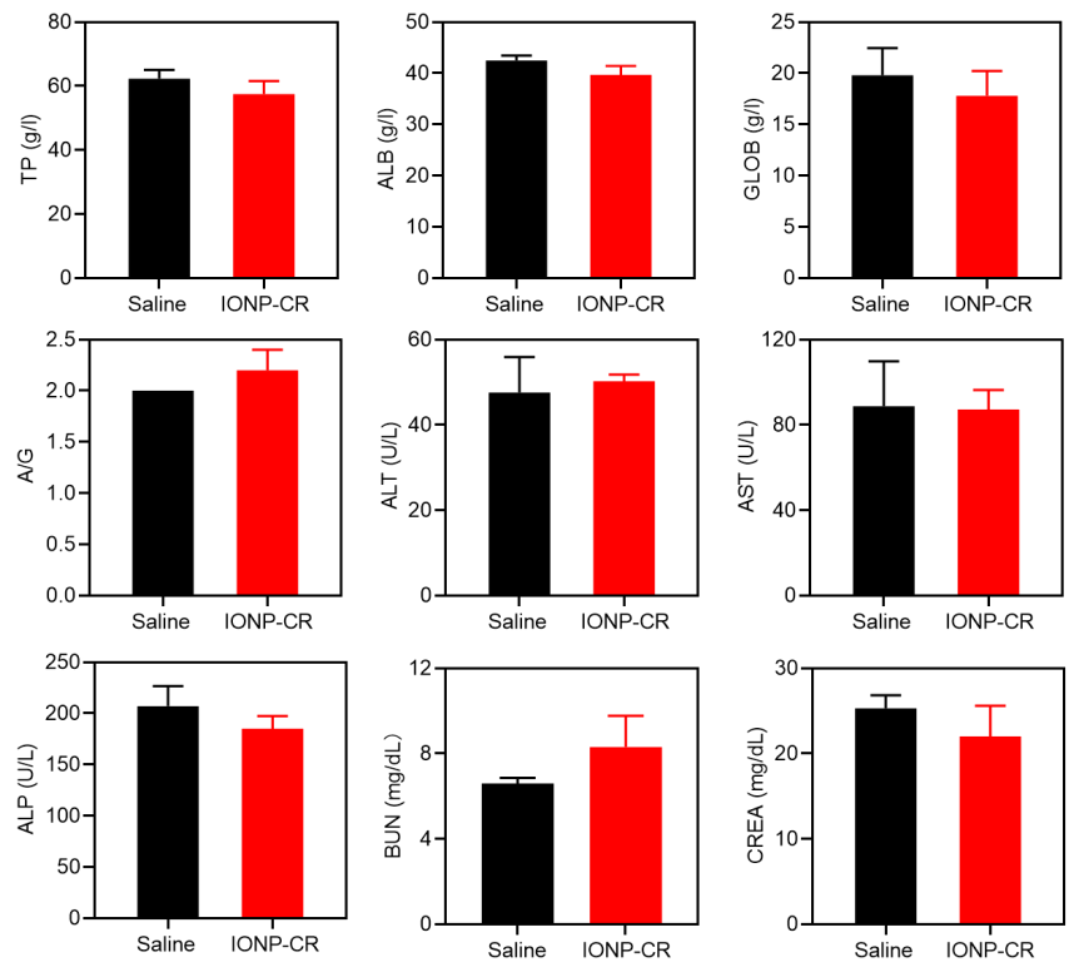

Figure S36. Biochemical blood analysis of the mice at 1 day after IONP-CR administration $(\mathrm{n}=3)$. 

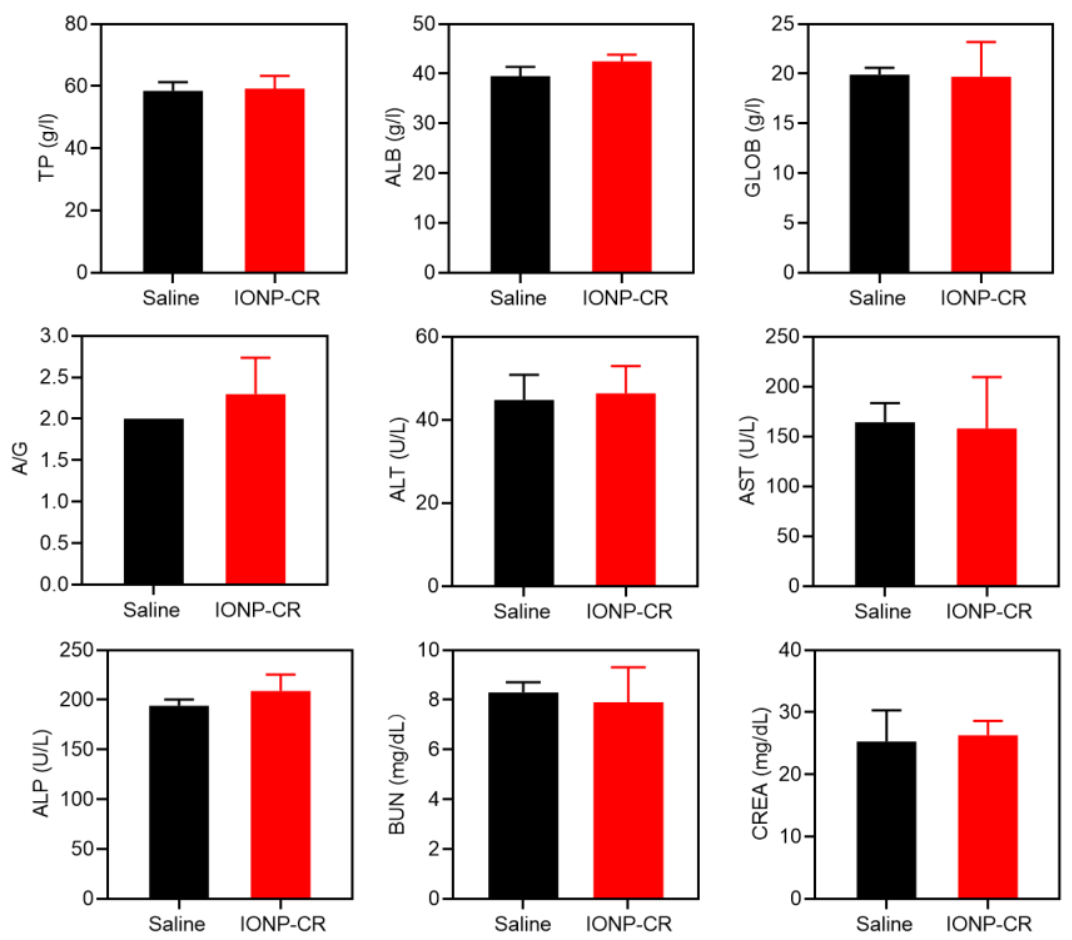

Figure S37. Biochemical blood analysis of the mice at 15 days after IONP-CR administration $(\mathrm{n}=3)$.
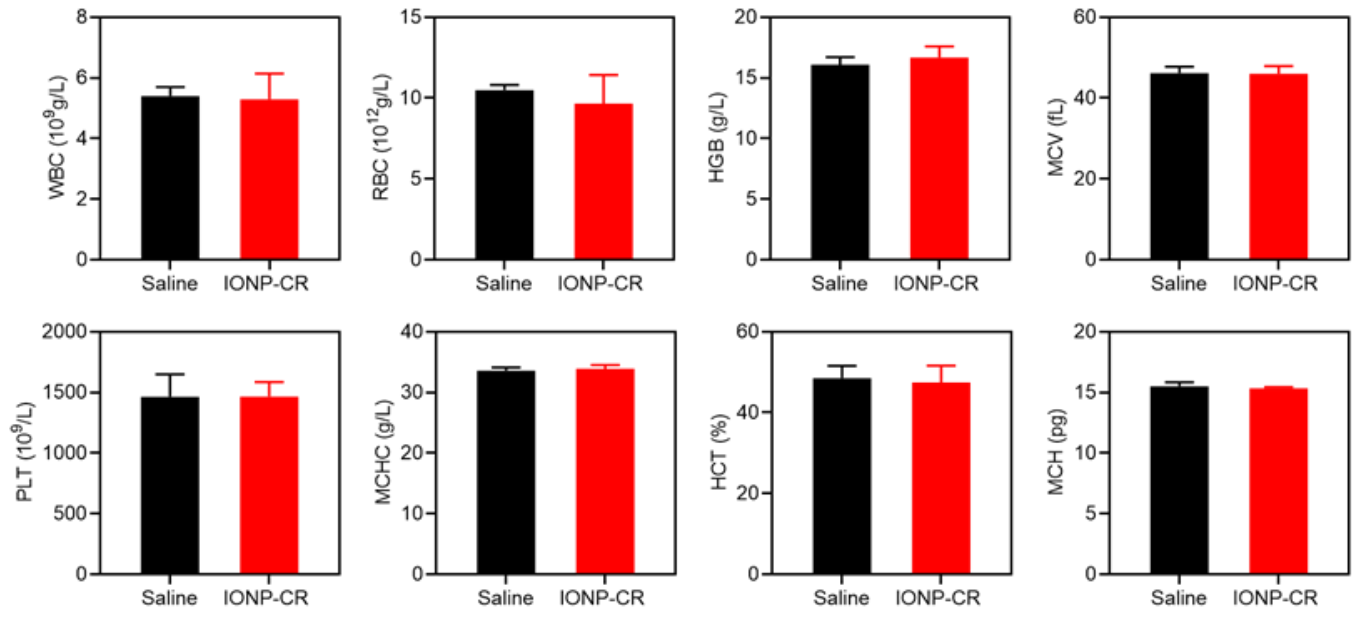

Figure S38. Hematological indices of the mice at 1 day after IONP-CR administration $(n=3)$. 

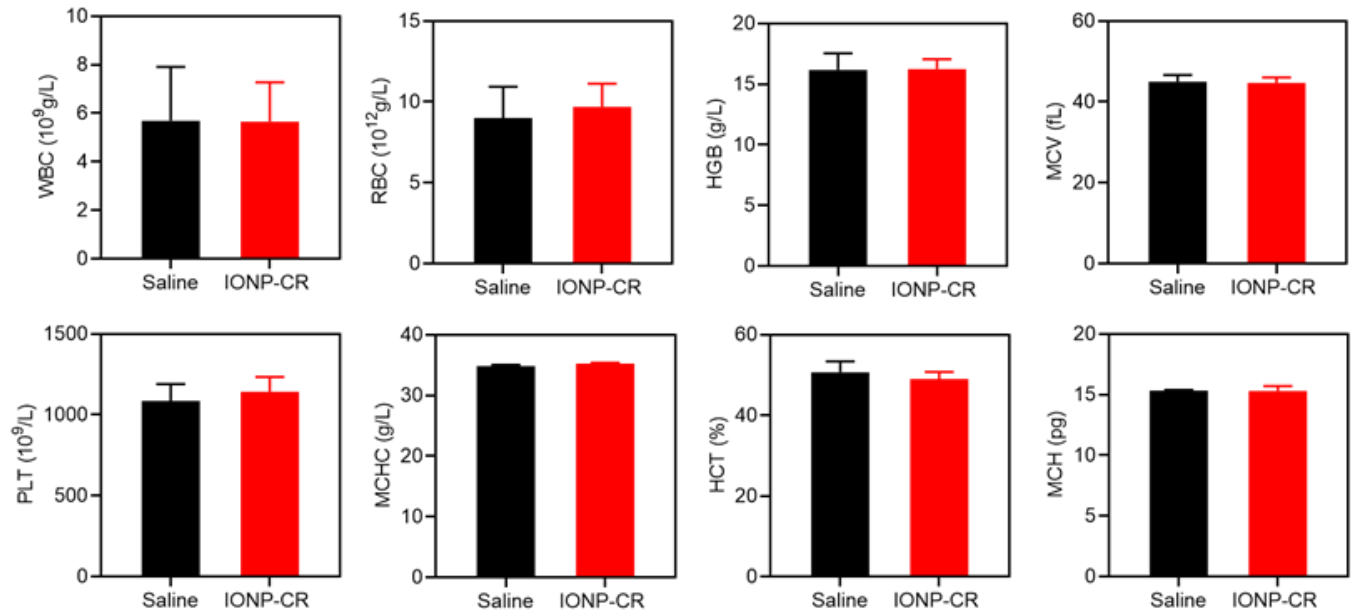

Figure S39. Hematological indices of the mice at 15 days after IONP-CR administration $(\mathrm{n}=3)$.

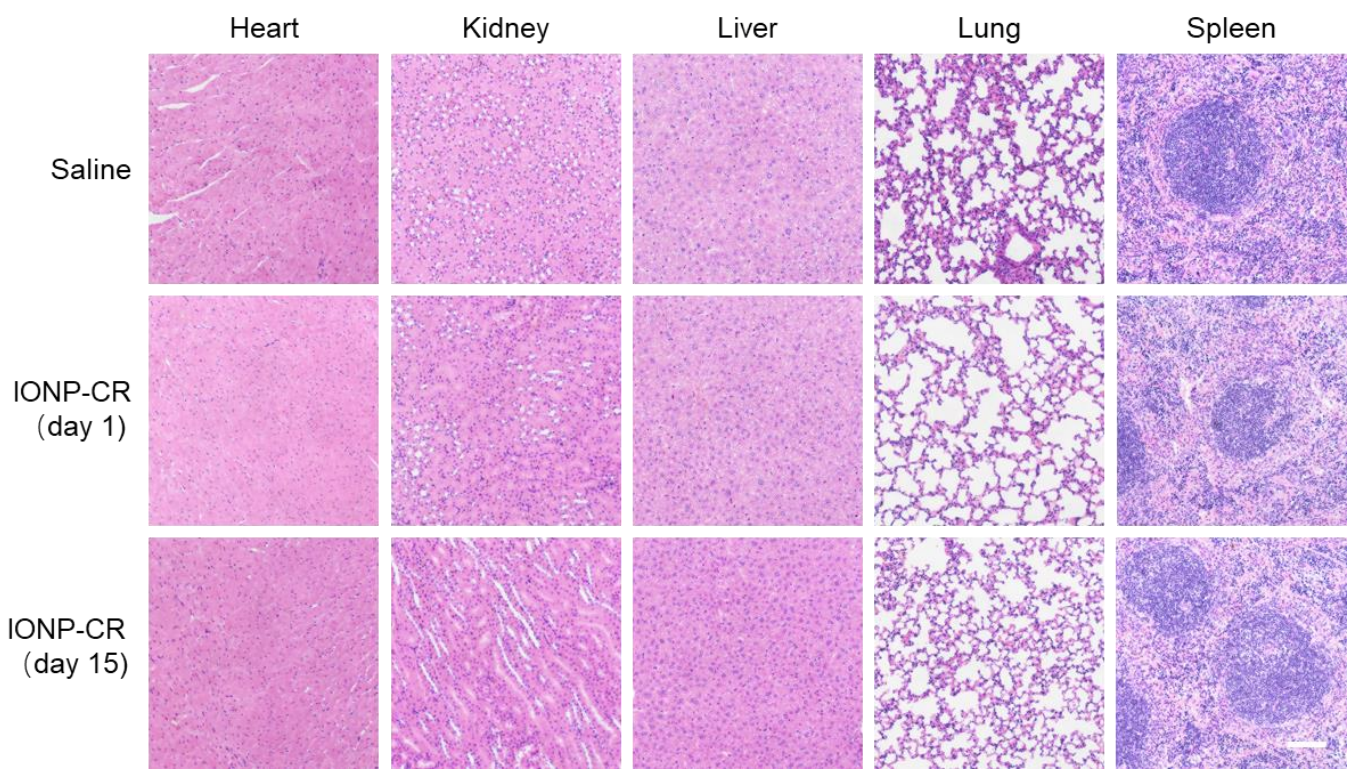

Figure S40. H\&E staining of tissues of the mice at 1 day and 15 days after IONP-CR administration $($ Scale bar $=200 \mu \mathrm{m})$. 
Table S1. Quantitative analysis of aCB and RGD conjugated on the nanoparticles.

\begin{tabular}{ccc}
\hline Sample & aCB per nanoparticle & RGD per nanoparticle \\
\hline IONP-CR & 68.7 & 51.5 \\
\hline MONP-CR & 19.2 & 13.7 \\
\hline GNR-CR & 897 & 700 \\
\hline
\end{tabular}




\section{References}

(1) Ma, D.; Zavalij, P. Y.; Isaacs, L., Acyclic cucurbit $[n]$ uril congeners are high affinity hosts. J. Org. Chem. 2010, 75, 4786-4795.

(2) Zhang, T.; Fan, H.; Zhou, J.; Liu, G.; Feng, G.; Jin, Q., Fluorescent conjugated polymer $\mathrm{PPESO}_{3}$ : A novel synthetic route and the application for sensing protease activities. Macromolecules 2006, 39, 7839-7843.

(3) Park, J.; An, K.; Hwang, Y.; Park, J.-G.; Noh, H.-J.; Kim, J.-Y.; Park, J.-H.; Hwang, N.-M.; Hyeon, T., Ultra-large-scale syntheses of monodisperse nanocrystals. Nat. Mater. 2004, 3, 891-895.

(4) Na, H. B.; Lee, J. H.; An, K. J.; Park, Y. I.; Park, M.; Lee, I. S.; Nam, D. H.; Kim, S. T.; Kim, S. H.; Kim, S. W.; Lim, K. H.; Kim, K. S.; Kim, S. O.; Hyeon, T., Development of a $\mathrm{T} 1$ contrast agent for magnetic resonance imaging using $\mathrm{MnO}$ nanoparticles. Angew. Chem., Int. Ed. 2007, 46, 5397-5401.

(5) Vigderman, L.; Khanal, B. P.; Zubarev, E. R., Functional gold nanorods: Synthesis, self-assembly, and sensing applications. Adv. Mater. 2012, 24, 4811-4841.

(6) Yu, Y.-P.; Wang, Q.; Liu, Y.-C.; Xie, Y., Molecular basis for the targeted binding of RGD-containing peptide to integrin $\alpha_{v} \beta_{3}$. Biomaterials 2014, 35, 1667-1675. 